\title{
Geologia
}

\section{G eoquímica e Petrogênese de Metabasitos do Grupo Votuverava (Terreno Apiaí, Cinturão Ribeira Meridional): Evidências de uma Bacia Retroarco Calimiana}

\author{
Geochemistry and Petrogenesis of Metabasites from the Votuverava Group (Apiaí \\ Terrane, Southern Ribeira Belt): Evidence of a Calymmian Back-arc Basin
}

\author{
Frederico Meira Faleiros ${ }^{1}$ (frederico.faleiros@cprm.gov.br), Viviane Carillo Ferrari ${ }^{1}$ (viviane.ferrari@ cprm.gov.br), \\ Vicente Sérgio Costa $^{1}$ (vicente.costa@ cprm.gov.br), G inaldo Ademar da Cruz Campanha² (ginaldo@usp.br) \\ ${ }^{1}$ Serviço G eológico do Brasil - CPRM \\ R. Costa 55, CEP 01304-010, São Paulo, SP, BR \\ ${ }^{2}$ Departamento de Mineralogia e Geotectônica - Instituto de G eociências - USP, São Paulo, SP, BR
}

Recebido em 12 de novembro de 2010; aceito em 11 de julho de 2011

\section{RESUMO}

O Grupo Votuverava (ca. 1500 - 1400 Ma) faz parte do Terreno Apiaí, um segmento do Cinturão Ribeira Meridional. É constituído por turbiditos distais com expressivo magmatismo básico representado por lentes concordantes de metabasito. Vinte amostras de metabasito foram investigadas por meio de análises geoquímicas (elementos maiores e traços). Três grupos $(\mathrm{G} 1, \mathrm{G} 2, \mathrm{G} 3)$ foram distinguidos com base em assinaturas $\mathrm{Ti} / \mathrm{V}$, padrões de elementos terras raras e perfis multielementos normalizados pelos valores de basaltos de dorsais meso-oceânicas (MORB). Todas as amostras apresentam assinaturas toleíticas. O G1 mostra assinatura de arco vulcânico, com razão Ti/V de 15 - 20, enriquecimento em íons litófilos de grande raio iônico (LILE) e empobrecimento em elementos de alta força de campo (HFSE) relativos ao MORB. O padrão dos elementos traços indica importante contribuição do componente de subducção. O G2 apresenta composição geral semelhante ao MORB, com Ti/V de 22 - 28. Contudo, o comportamento dos elementos traços sugere uma pequena contribuição do componente de subducção. O G3 apresenta assinatura de basaltos do tipo MORB enriquecido, com razão Ti/V ao redor de 40 e enriquecimento em LILE e HFSE. A variabilidade entre as razões $\mathrm{TiO}_{2} / \mathrm{Yb}$ e $\mathrm{Nb} / \mathrm{Yb}$ sugere que as rochas G1 e G2 foram geradas por fusão rasa (fontes mantélicas tipo MORB normal e enriquecido, respectivamente). As rochas G3 são enriquecidas em Ti e Nb, sugerindo interação entre fontes do tipo MORB e pluma. A coexistência de metabasitos com composições de basaltos toleíticos de arcos vulcânicos e basaltos de dorsais meso-oceânicas, os padrões geoquímicos de forma geral e o ambiente de sedimentação do Grupo Votuverava são consistentes com um ambiente de bacia retroarco.

Palavras-chave: Grupo Votuverava; Metabasitos; Geoquímica; Petrogênese; Terreno Apiaí; Cinturão Ribeira Meridional.

\section{ABSTRACT}

The Votuverava Group (ca. 1500 - 1400 Ma), which is part of the Apiaí Terrane, a segment of the Southern Ribeira Belt, is composed of distal turbidites with significant basic magmatism represented by concordant lenses of metabasite. Twenty metabasite samples were investigated using geochemical analyses (major and trace elements). Three groups (G1, G2, G3) were identified based on Ti/V ratios, rare earth element patterns and MORB-normalized multi-element diagrams. All samples have tholeiitic signatures. The G1 group has a volcanic arc signature, with Ti/V ratios of $15-20$, enrichment of large ion lithophile elements (LILE) and depletion in high field strength elements (HFSE) relative to the MORB. The trace element pattern indicates an important contribution of the subduction component. The G2 group has a MORBtype composition, with $\mathrm{Ti} / \mathrm{V}$ ratios of 22 - 28. Nevertheless, the trace element behavior indicates a small contribution of the subduction component. The G3 group has an enriched MORB signature, with Ti/V ratio of approximately 40 and enrichment of LILE and HFSE. The variability of the $\mathrm{TiO}_{2} / \mathrm{Yb}$ and $\mathrm{Nb} / \mathrm{Yb}$ ratios suggests that the G1 and G2 rocks 
were generated by shallow melting (N-MORB and E-MORB mantle sources, respectively). The G3 rocks are enriched in Ti and Nb, suggesting interaction between MORB and plume mantle sources. The coexistence of volcanic arc basalt and mid-ocean ridge basalt compositions, the overall geochemical patterns, and the sedimentary environment of the Votuverava Group are consistent with a backarc basin environment.

Keywords: Votuverava Group; Metabasites; Geochemistry; Petrogenesis; Apiaí Terrane; Southern Ribeira Belt.

\section{INTRODUÇÃO}

O Cinturão Ribeira compreende um largo segmento crustal paralelo à linha costeira do sudeste brasileiro (Figura 1), tendo sido amalgamado, deformado e metamorfizado durante a Orogenia Brasiliano-Pan Africana (Neoproterozoico ao início do Paleozoico). Consiste de um complexo orógeno colisional relacionado às colisões oblíquas entre os crátons Paranapanema, São Francisco e Congo e à consolidação do continente Gondwana Ocidental (Brito Neves, Campos Neto, Fuck, 1999; Campanha e Brito Neves, 2004; Fuck, Brito Neves, Schobbenhaus, 2008).

O Cinturão Ribeira teve sua estruturação principal controlada por um sistema de cisalhamento transcorrente tardio paralelo ao orógeno (e.g., Sadowski, 1991; Dürr e Dingeldey, 1996; Campanha, 2002; Egydio-Silva et al., 2002; Campanha e Brito Neves, 2004; Faleiros et al., 2007, 2010). Como resultado, o cinturão é dominado por terrenos tectono-estratigráficos (no sentido de Howell, 1995) de origem diversa, limitados por zonas de falha (e.g., Heilbron et al., 2004; Campanha e Faleiros, 2005; Faleiros, 2008; Faleiros et al., 2011). Atualmente sabe-se que o Cinturão Ribeira inclui rochas de embasamento arqueanas a paleoproterozoicas, suítes de rochas sedimentares e vulcanossedimentares mesoproterozoicas e neoproterozoicas, suítes graníticas intrusivas neoproterozoicas, interpretadas como associações de arcos magmáticos, sequências sedimentares de margens passivas e granitos tardi-cinemáticos (e.g., Campos Neto e Figueiredo, 1995; Campanha e Sadowski, 1999; Janasi, Leite, Van Schmus, 2001; Heilbron e Machado, 2003; Heilbron et al., 2004, 2010; Silva et al., 2005; Prazeres Filho, 2005).

Apesar desta configuração complexa, os modelos de evolução tectônica regional para o Cinturão Ribeira Meridional classicamente apresentavam aproximações relativamente fixistas, onde diferentes unidades de rochas metassedimentares e de embasamento gnáissico, limitadas por zonas de falha foram tentativamente correlacionadas. Desde a década de 1980 o Cinturão Ribeira Meridional tem sido interpretado à luz dos conceitos da tectônica de placas (e.g., Soares, 1987, 1988; Campanha, Bistrichi, Almeida, 1987; Campanha, 1991; Basei et al., 1992; Reis Neto, 1994; Siga Júnior, 1995; Fassbinder, 1996; Campanha e Sadowski, 1999). Contudo, esses trabalhos assu- mem que as relações espaciais atualmente observadas entre os terrenos justapostos representam relações genéticas (paleogeografia parcialmente preservada). Além disso, a união dos dados geocronológicos e de geoquímica isotópica obtidos recentemente (Hackspacher et al., 2000; Harara, 2001; Oliveira et al., 2002; Sato et al., 2003, 2009; Basei et al., 2003, 2008; Siga Junior et al., 2007, 2009, 2011; Weber et al., 2004; Campanha et al., 2008a, 2008b, 2009; Faleiros, 2008; Cury, 2009) contradiz esta interpretação. Os dados disponíveis mostram um cenário complexo que não pode ser explicado por reconstruções baseadas em eventos simples de abertura e inversão de bacias oceânicas, ou de Ciclo de Wilson (Faleiros, 2008; Faleiros et al., 2011). Os dados sugerem que a região como um todo consiste de uma complexa colagem de vários terrenos suspeitos e/ou exóticos (no sentido de Coney, Jones, Monger, 1980; McWillians e Howell, 1982; Schermer, Howell, Jones, 1984; Howell, 1995). Neste contexto, a reconstrução da história evolutiva de terrenos individuais com base em estudos detalhados é de fundamental importância para o entendimento da evolução geotectônica regional.

Neste trabalho apresentamos dados geoquímicos de metabasitos associados a unidades do Grupo Votuverava, um terreno tectono-estratigráfico integrante do Terreno Apiaí, Cinturão Ribeira Meridional. Os dados obtidos trazem importantes informações petrogenéticas que permitem um grande avanço na definição do ambiente tectônico de geração do Grupo Votuverava, com implicações para evolução geotectônica regional.

\section{CONTEXTO GEOLÓGICO DO GRUPO VOTUVERAVA}

\section{Geologia regional}

O Grupo Votuverava se estende do sul do Estado de São Paulo ao leste do Estado do Paraná e faz parte do Terreno Apiaí, um segmento do Cinturão Ribeira Meridional (Figura 1).

O Terreno Apiaí consiste de um terreno composto no sentido de Howell (1995) limitado ao sul pela Falha da Lancinha, que o separa do Terreno Curitiba (Faleiros, 2008). Sua porção norte é recoberta por rochas fanerozoicas da Bacia do Paraná. Dados geocronológicos recentes (Hackspacher 

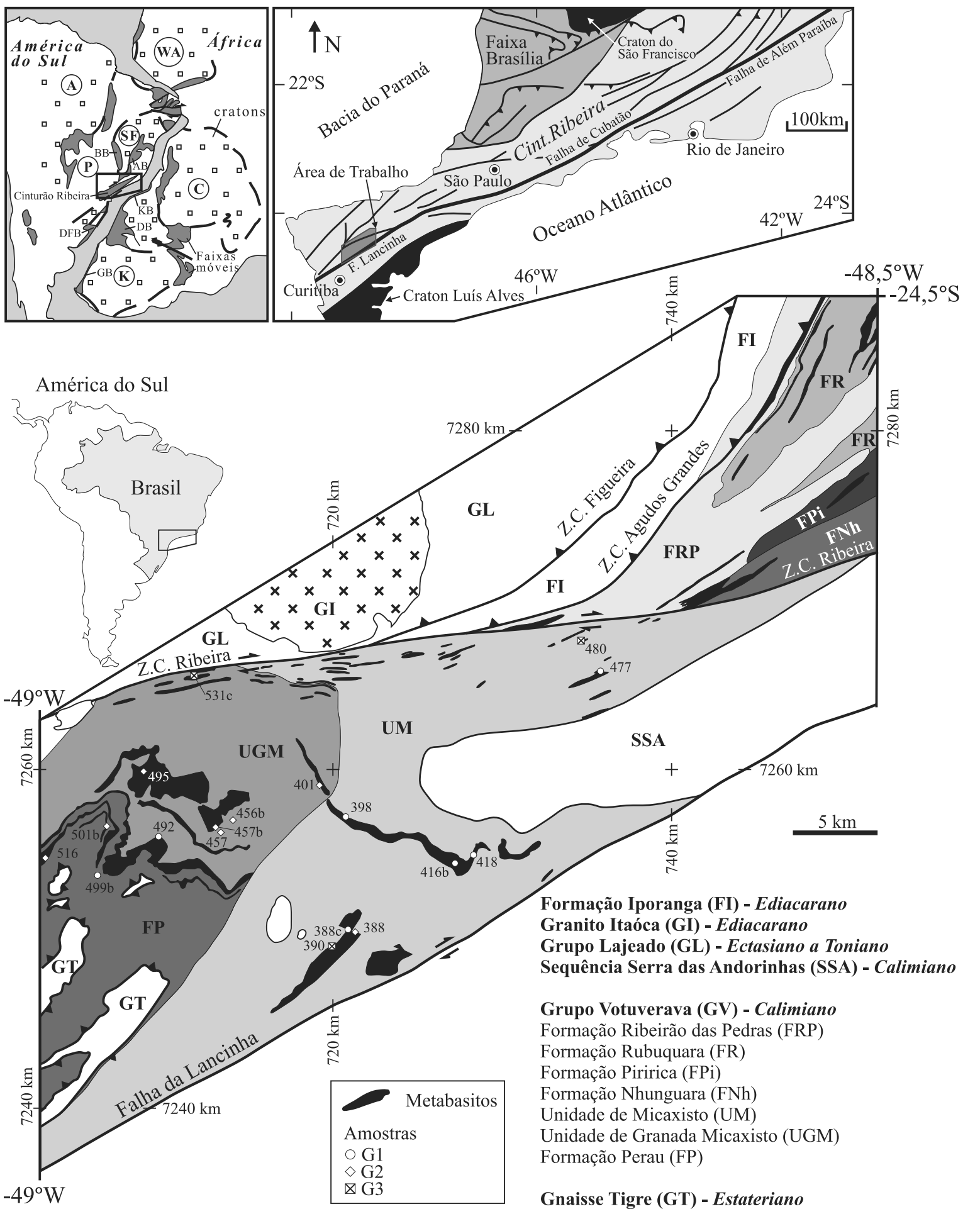

Figura 1. Mapa geológico simplificado com estações de amostragem de metabasitos do G rupo Votuverava. Abreviações: Crátons: África O este (WA), Congo (C), Kalahari (K), Paranapanema (P), São Francisco (SF), Amazônico (A). Faixas móveis: Damara (DB), Kaoko (KB), G ariep (GB), Dom Feliciano (DFB), Araçuaí (AB), Brasília (BB). G rupo Votuverava: Formação Perau (FP), Unidade de Micaxisto (UM); Unidade de Granada Micaxisto (UGM), Formação Ribeirão das Pedras (FRP), Formação N hunguara (FN h), Formação Piririca (FPi), Formação Rubuquara (FR). Demais unidades: Sequência Serra das Andorinhas (SSA), Grupo Lajeado (GL), Formação Iporanga (FI), Granito Itaóca (GI), G naisse Tigre (GT). 
et al., 2000; Oliveira et al., 2002; Basei et al., 2003; Weber et al., 2004; Campanha et al., 2008a, 2008b, 2009; Siga Júnior et al., 2009, 2011) indicam que o Terreno Apiaí foi formado pela amalgamação de unidades de rochas metassedimentares e metavulcano-sedimentares de idades calimiana (ca. 1500 - 1400 Ma: formações Água Clara e Betara e Grupo Votuverava), ectasiana a toniana (entre 1400 e $880 \mathrm{Ma}$ Grupo Lajeado), toniana (ca. 1000 - 900 Ma: parte do Grupo Itaiacoca) e ediacarana (ca. 630 - $580 \mathrm{Ma}$ : parte do Grupo Itaiacoca e Formação Iporanga). Contudo, não se sabe ao certo se esta amalgamação ocorreu essencialmente no Brasiliano, ou se parte das unidades mais antigas (mesoproterozoicas) foram amalgamadas durante outro evento tectônico. Compõem ainda o Terreno Apiaí pequenos núcleos de embasamento gnáissico presentes em algumas janelas estruturais. Nos núcleos Tigre e Betara afloram sienogranitos heterogeneamente milonitizados com assinaturas geoquímicas de granitos anorogênicos tipo A e idades U-Pb em zircão de $1772 \pm 10 \mathrm{Ma}$ e $1748 \pm 5 \mathrm{Ma}$, respectivamente (Cury et al., 2002). Metabasitos presentes no Núcleo Betara apresentaram idade U-Pb em zircão de $1790 \pm 22$ Ma (Siga Júnior et al., 2011). Completa o quadro estratigráfico suítes intrusivas graníticas ediacaranas formadas em fases pré, sin e pós-colisionais (Janasi, Leite, Van Schmus, 2001; Prazeres Filho, 2005).

\section{Geologia do Grupo Votuverava}

O Grupo Votuverava foi definido originalmente como formação por Bigarella e Salamuni (1958). É limitado ao sul pela Falha da Lancinha e ao norte pelas zonas de cisalhamento Figueira e Ribeira (Figura 1). Constitui uma sequência essencialmente vulcano-sedimentar formada por metapelitos rítmicos (ardósia e filito) e micaxisto, interpretados como um complexo turbidítico distal (Pires, 1988; Campanha e Sadowski, 1999), com magmatismo básico expressivo, representado na forma de intercalações lenticulares de metabasitos concordantes com a estrutura primária (anfibólio xisto/fels, anfibolito). Em trabalho de mapeamento geológico na escala 1:100.000 o Grupo Votuverava foi subdividido em cinco formações (Perau, Rubuquara, Nhunguara, Piririca e Ribeirão das Pedras; conforme Perrota, 1996) e duas unidades informais (unidades de micaxisto e granada micaxisto) (Faleiros, Morais, Costa, 2011). Destaca-se na Formação Perau a presença de camadas de filito carbonoso com intercalações de metatufo félsico, lentes com sulfetos polimetálicos maciços ou disseminados de $\mathrm{Pb}-\mathrm{Zn}$-Ag-Fe (galena, esfalerita, pirita, pirrotita e calcopirita), lentes baritíferas, formações ferríferas fácies magnetita, metachert, turmalinito e conglomerado. $\mathrm{O}$ ambiente desta formação é propício a acumulações de $\mathrm{Cu}, \mathrm{Pb}, \mathrm{Zn}, \mathrm{Au}, \mathrm{Ag}$ e barita, como nas minas do Perau, Ca- noas e Pretinho. Daitx (1996) interpreta que a presença de litotipos regionalmente incomuns indica condições particulares de sedimentação e vulcanismo associados a bacias tectônicas restritas.

As rochas do Grupo Votuverava passaram por metamorfismo barroviano variando de condições de fácies xisto verde inferior (zona da clorita) nas unidades ao norte da Zona de Cisalhamento Ribeira a condições de fácies anfibolito médio (zona da cianita) ao sul desta estrutura (Faleiros et al., 2010). Dados geotermobarométricos obtidos em rochas da Unidade de Granada Micaxisto indicaram condições entre 550 e $630^{\circ} \mathrm{C}$ e 6 e 8 kbar (Faleiros et al., 2010).

Dados geocronológicos U-Pb em zircão de metabasitos de diferentes unidades forneceram idades calimianas: $1484 \pm 16$ Ma (Formação Perau, Basei et al., 2003), 1479 \pm 12 Ma (Unidade de Granada Micaxisto, Basei et al., 2003) e $1439 \pm 19$ Ma (Formação Rubuquara, Campanha et al., 2008b, 2009). Zircões detríticos extraídos de metapelito da Unidade de Granada Micaxisto forneceram idades U-Pb laser-ablation mínimas ao redor de 1510 Ma (F.M. Faleiros, dados inéditos), interpretadas como as idades máximas de sedimentação.

\section{Metabasitos do Grupo Votuverava}

Macroscopicamente ocorrem dois tipos principais de metabasitos, um de granulação fina, estrutura xistosa ou isótropa e cor verde claro a médio; e outro de granulação média a grossa, estrutura lenticularizada (muitas vezes milonítica), de cor verde escuro a negra. Ao microscópio petrográfico esses dois litotipos correspondem a associações de graus metamórficos contrastantes, sendo o primeiro formado pela associação actinolita + clorita + epidoto + quartzo \pm plagioclásio \pm carbonato (fácies xisto verde) e o outro pela associação hornblenda (tschermakita) + plagioclásio (andesina) + quartzo \pm actinolita \pm epitodo (fácies anfibolito). Minerais acessórios comuns compreendem titanita, óxidos de titânio (titanomagnetita, ilmenita e, localmente, rutilo) e apatita. Os anfibolitos exibem textura nematoblástica formada por anfibólio com hábito prismático orientado segundo uma direção preferencial. Porfiroblastos (1 a $2 \mathrm{~mm}$ ) de hornblenda, plagioclásio e minerais opacos destacam-se em algumas amostras. Nos anfibolitos o plagioclásio e o quartzo comumente formam leitos de textura granoblástica definindo mosaicos alternados com bandas ricas em anfibólios. Os porfiroblastos de anfibólio presentes nos metabasitos de fácies anfibolito em geral exibem zoneamento textural e químico relacionado à progressão do metamorfismo, com composições de actinolita nos núcleos e tschermakita nas bordas dos cristais (Faleiros et al., 2010). Nos metabasitos de fácies xisto verde predominam texturas isótropas. Localmente ocorrem texturas ígneas subofíticas preservadas e restos de clinopiroxênio 
e hornblenda ígnea reliquiares. A hornblenda ígnea apresenta cor castanho escuro, ocorre exclusivamente em metabasitos de fácies xisto verde e apresenta-se em desequilíbrio com as associações de minerais metamórficos. É petrograficamente muito distinta em relação à hornblenda metamórfica dos metabasitos de fácies anfibolito, que apresenta cor verde escuro azulado. Análises químicas minerais realizadas em amostras de metabasitos do Grupo Votuverava, coletadas em áreas adjacentes à área de estudos deste trabalho (Maniesi, 1997; Faleiros e Campanha, dados inéditos) revelaram composição variando de edenítica a hornblenda pargasítica e pargasítica ferrosa para o anfibólio castanho escuro, corroborando a natureza ígnea.

\section{LITOGEOQUÍMICA}

Análises químicas de vinte amostras de metabasito de três unidades do Grupo Votuverava (Figura 1, Tabela 1) foram efetuadas incluindo elementos maiores, traços e terras raras nos laboratórios da ACME (Canadá). Foram analisadas oito amostras da Unidade de Micaxisto (UM), oito amostras da Unidade de Granada Micaxisto (UGM) e quatro amostras da Formação Perau (FP). Para as análises químicas foram selecionadas amostras sem evidências petrográficas de alteração intempérica ou metassomática. Óxidos maiores foram obtidos por espectrometria de emissão ICP (Inductively coupled plasma) e elementos traços e terras raras por espectrometria de massa ICP. A perda ao fogo foi obtida por diferença após ignição a $1.000^{\circ} \mathrm{C}$.

Os metabasitos analisados podem ser subdivididos em três grupos (G1, G2 e G3) com base na variabilidade da razão Ti/V (Figura 2). G1 apresenta valores Ti/V entre 15 e 20, característicos de basaltos toleíticos de arcos de ilhas (Shervais, 1982), enquanto G2 e G3 apresentam valores $\mathrm{Ti} / \mathrm{V}$ de 22 - 28 e $\sim 40$, respectivamente, mostrando assinaturas de basaltos de fundo oceânico (MORB) (Shervais, 1982). O possível significado geológico desta subdivisão será discutido abaixo, com base nos comportamentos dos elementos maiores, traços e terras raras. Petrograficamente, G1 e G2 são relativamente enriquecidos em titanita, plagioclásio e quartzo em relação ao G3, enquanto minerais opacos (titanomagnetita e ilmenita) são raros a ausentes. G3 é rico em minerais opacos.

A Figura 2 mostra que não ocorre nenhuma correlação entre o grau metamórfico, a unidade geológica e a assinatura geoquímica.

\section{Testes para identificar modificações metassomáticas}

Possíveis efeitos de modificações metassomáticas foram avaliados utilizando o método gráfico de Beswick e Soucie
(1978) (Figura 3). O método utiliza diagramas envolvendo razões de proporções moleculares logarítmicas dos elementos maiores e consiste em comparar o padrão das amostras analisadas frente às tendências definidas a partir de dados químicos de rochas ígneas fanerozoicas livres de metamorfismo e alteração. As tendências definidas por Beswick e Soucie (1978) independem da afinidade geoquímica das suítes (toleítica, calcioalcalina ou alcalina).

Na Figura 3 a maioria das amostras se distribui nos campos definidos pelas rochas não alteradas, sugerindo que as composições, de maneira geral, aproximam-se das composições ígneas originais. Nos gráficos relacionando a razão $\mathrm{SiO}_{2} / \mathrm{K}_{2} \mathrm{O}$ (Figuras $3 \mathrm{a}$ e $3 \mathrm{~b}$ ) as amostras apresentam tendências paralelas aos campos definidos pelas rochas não modificadas, porém, ligeiramente acima destes. Isso sugere limitado ganho de $\mathrm{SiO}_{2}$ para a maioria das amostras. Desvios significativos com relação aos conteúdos de $\mathrm{Na}_{2} \mathrm{O}$ e $\mathrm{CaO}$ ocorrem para as amostras 499B (perda e ganho, respectivamente), 388C (ganho e perda, respectivamente) e 514B (ganho e perda, respectivamente) (Figuras $3 \mathrm{~b}$ a $3 \mathrm{~d}$ ). A amostra 501B aparece no limite inferior das tendências em todos os gráficos que relacionam razões com o $\mathrm{K}_{2} \mathrm{O}$ no denominador (Figuras $3 \mathrm{a}, 3 \mathrm{~b}$ e $3 \mathrm{~d}$ a $3 \mathrm{f}$ ) e, associado a um teor relativamente anômalo de $\mathrm{K}_{2} \mathrm{O}$, isso pode sugerir ganho de $\mathrm{K}_{2} \mathrm{O}$.

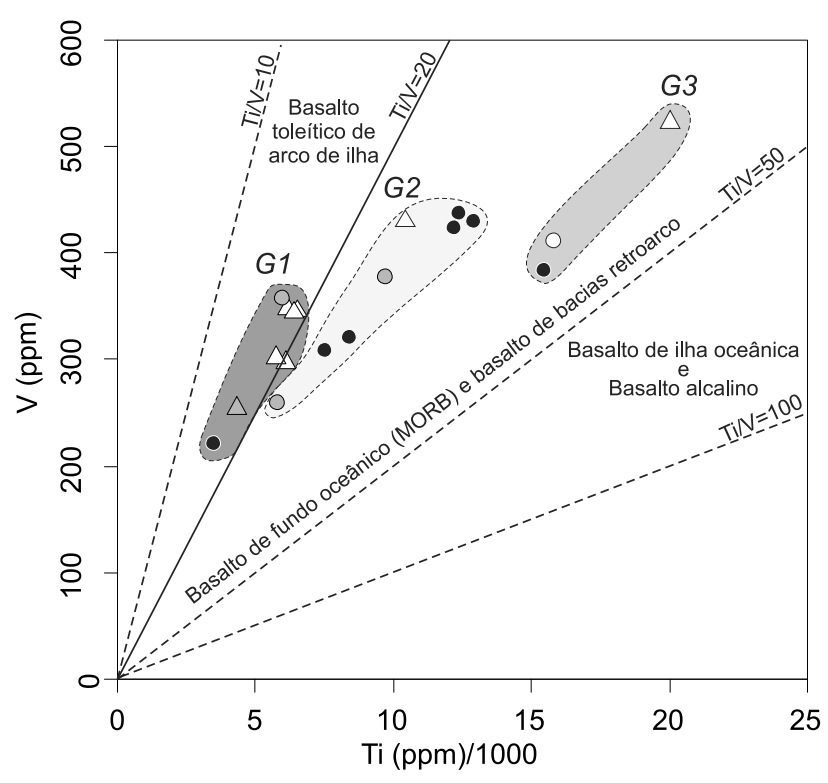

Figura 2. Diagrama discriminante de basaltos de diferentes ambientes tectônicos baseado na relação Ti/V (Shervais, 1982) com dados dos metabasitos do Grupo Votuverava. Círculos (fácies anfibolito), triângulos (fácies xisto verde), preenchimento preto (Unidade de Granada Micaxisto), branco (Unidade de Micaxisto), cinza (Formação Perau). 


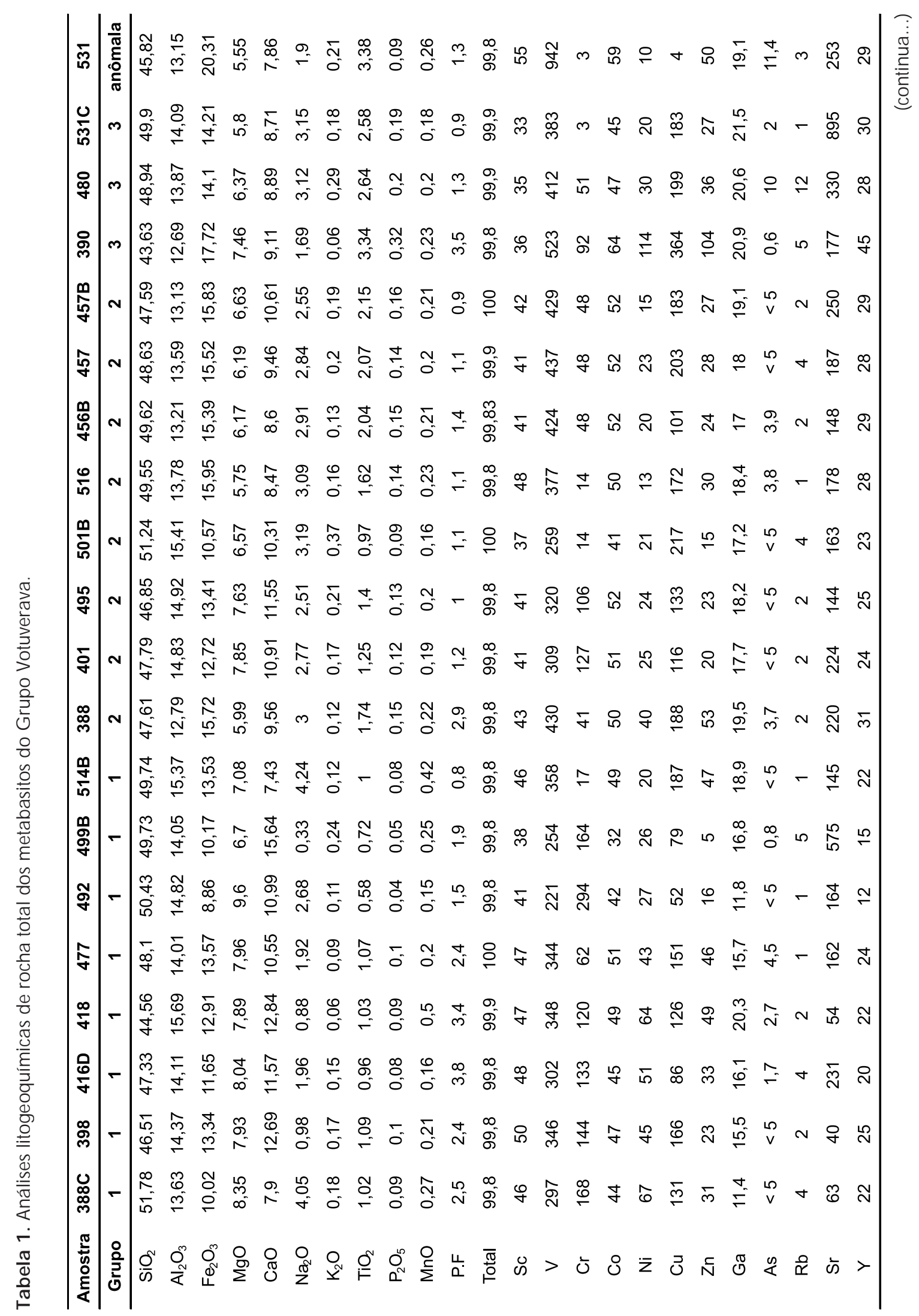




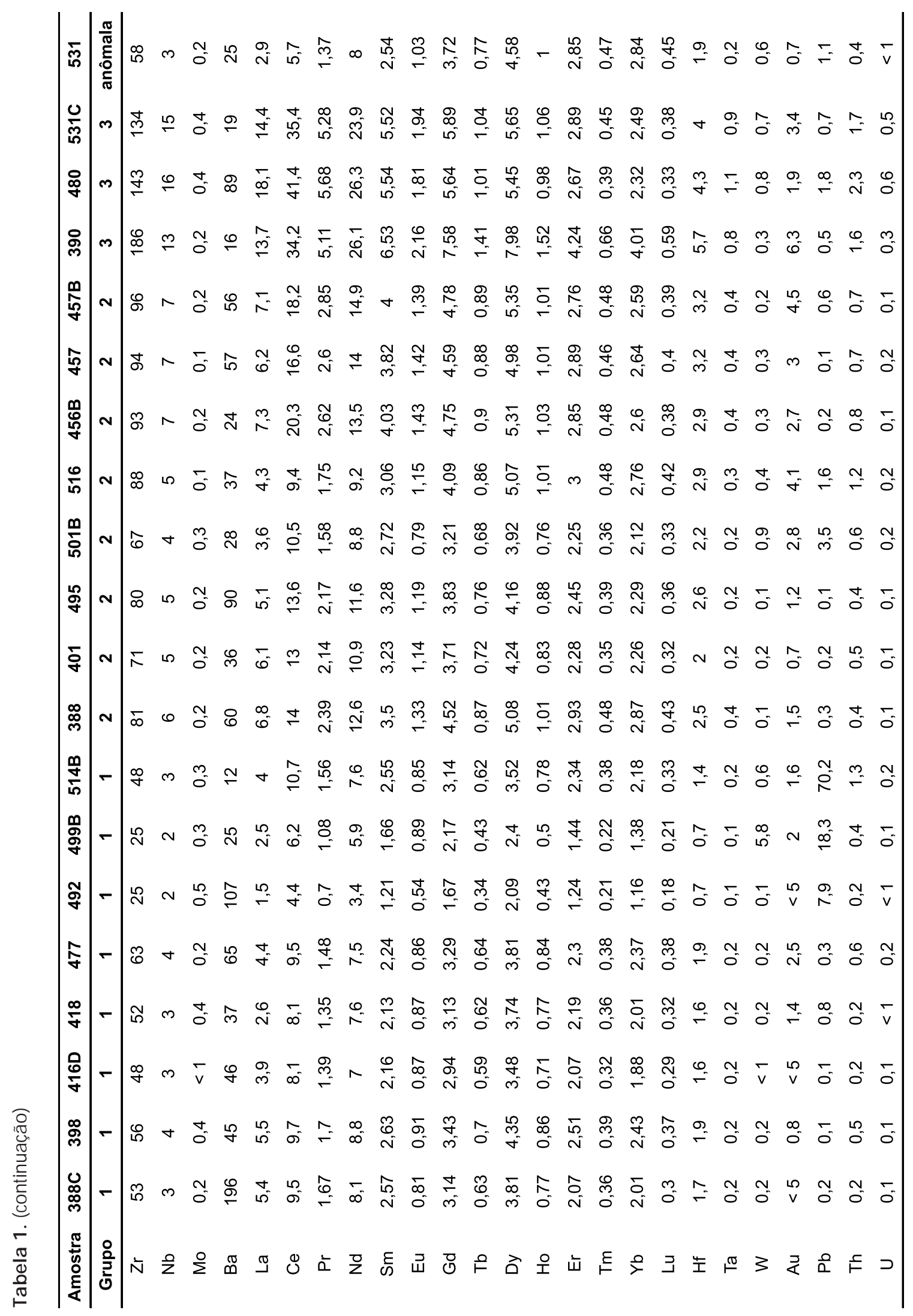




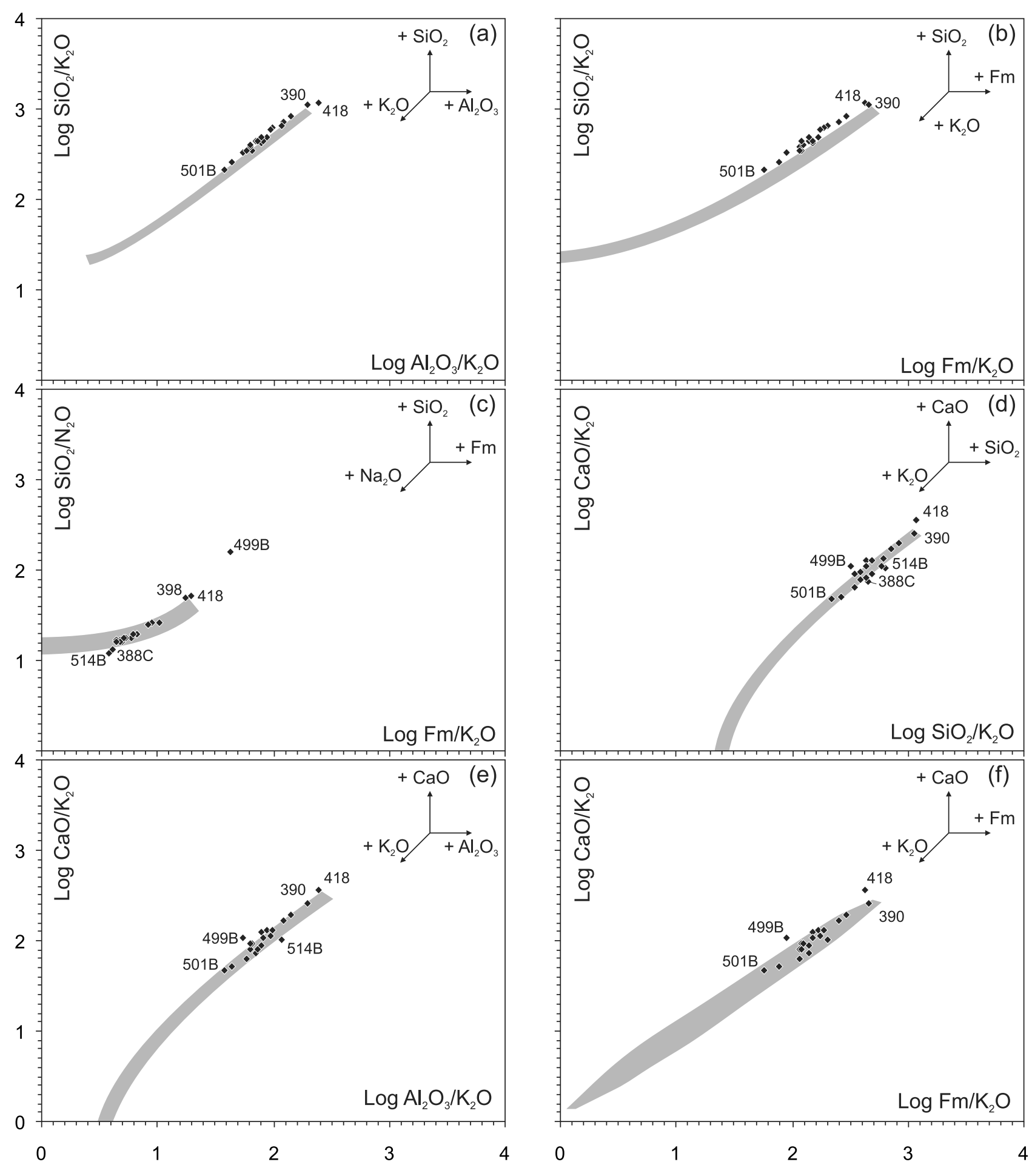

Figura 3. Diagramas de proporção molecular logarítmica (Beswick e Soucie, 1978) com os teores dos metabasitos do G rupo Votuverava. $\mathrm{Fm}=\mathrm{FeO}_{\mathrm{T}}+\mathrm{MgO}+\mathrm{MnO}$. 
O comportamento dos elementos maiores e traços das amostras 499B, 388C, 514B e 501B de forma geral corroboram os efeitos de modificações metassomáticas sugeridas pelos testes acima. Assim, os dados analíticos destas amostras serão doravante desconsiderados.

Algumas das demais amostras (e.g., 398, 418) se desviam ligeiramente das tendências definidas por Beswick e Soucie (1978). Contudo, a análise destas amostras em diagramas binários relacionando o índice de diferenciação de Thornton e Tuttle (1960) (ID = Qtz $+\mathrm{Ab}+\mathrm{Or}+\mathrm{Ne}+\mathrm{Lct}$ + Kls normativos) e os óxidos em porcentagem e peso (Figura 4) não mostra desvios significativos em relação ao padrão de evolução das amostras não modificadas e os dados destas amostras não foram desconsiderados.

A Tabela 2 sumariza os resultados obtidos pelos testes de modificações metassomáticas e relaciona teores anômalos de óxidos e elementos traços, incluindo amostras cujo teste de Beswick e Soucie (1978) não revelou alteração evidente.

\section{Elementos maiores}

O teor de $\mathrm{SiO}_{2}$ dos metabasitos varia de 44 a $51 \%$, mostrando composição básica. Todas as amostras apresentam quartzo normativo. Do G1 ao G3 ocorre aumento relativo dos conteúdos de $\mathrm{Fe}_{2} \mathrm{O}_{3}, \mathrm{TiO}_{2}$ e $\mathrm{P}_{2} \mathrm{O}_{5}$, e diminuição dos teores de $\mathrm{MgO}$ e $\mathrm{CaO}$ (Tabela 1).

Os diagramas binários relacionando ID e os elementos maiores (Figura 4) ilustram a evolução magmática dos três conjuntos de metabasitos. Desconsiderando algumas amostras com teores anômalos, ocorrem tendências magmáticas coerentes para a relação entre ID e todos os elementos maiores analisados (Figura 4). O comportamento de parte dos elementos maiores $\left(\mathrm{SiO}_{2}, \mathrm{Al}_{2} \mathrm{O}_{3}, \mathrm{CaO}, \mathrm{Na}_{2} \mathrm{O}\right.$, $\mathrm{Fe}_{2} \mathrm{O}_{3}$ e $\mathrm{MgO}$ ) pode ser interpretado como sugestivo de uma evolução semelhante, e talvez cogenética, para os metabasitos G1, G2 e G3 (Figura 4), de forma que G1 representaria os líquidos mais primitivos e G2 e G3 os mais evoluídos. Entretanto, o G3 apresenta conteúdos consideravelmente maiores de $\mathrm{TiO}_{2}$ e $\mathrm{P}_{2} \mathrm{O}_{5}$, o que pode sugerir uma evolução distinta (Figura 4).

Considerando os três grupos conjuntamente ocorrem correlações negativas entre DI vs. $\mathrm{Al}_{2} \mathrm{O}_{3}$ e $\mathrm{CaO}$, o que sugere um controle pelo fracionamento de plagioclásio. Entretanto, as amostras G3 definem uma tendência de correlação positiva entre $\mathrm{DI}$ e $\mathrm{Al}_{2} \mathrm{O}_{3}$. O gráfico relacionando DI e $\mathrm{MgO}$ apresenta padrão horizontal para $\mathrm{G} 1$, com exceção da amostra 492, com teor anômalo de $\mathrm{MgO}$, e correlação negativa para $\mathrm{G} 2$ e $\mathrm{G} 3$. $\mathrm{TiO}_{2}$ e $\mathrm{P}_{2} \mathrm{O}_{5}$ tiveram comportamentos incompatíveis ao longo de toda a evolução de G1, G2 e G3.

Todas as amostras (G1, G2 e G3) se posicionam no campo toleítico no diagrama AFM (Irvine e Baragar,
1971) (Figura 5). A análise dos elementos maiores no diagrama $\mathrm{SiO}_{2}$ versus álcalis (Figura 6) mostra composições características de rochas básicas vulcânicas (conteúdo de sílica menor que 51\%) classificadas como basaltos subalcalinos/toleíticos. O G1 apresenta alcalinidade menor que o G2 e o G3 (Figura 6).

\section{Elementos traços}

A principal característica mostrada pelo comportamento dos elementos traços é um aumento nos conteúdos dos elementos de alta força de campo (HFSE - high field strength elements) ( $\mathrm{Zr}, \mathrm{Y}, \mathrm{Hf}, \mathrm{Nb}, \mathrm{Nd}, \mathrm{Ta}$ ) do G1 ao G3 (Tabela 1). Os diagramas relacionando DI e os elementos traços apresentam tendências de correlação condizentes com uma evolução ígnea, na maioria dos casos. Ocorrem correlações negativas entre DI versus $\mathrm{Cr}$ e Ni (Figuras $7 \mathrm{a}$ e $7 \mathrm{~b}$ ), mostrando que estes elementos se comportaram como compatíveis, o que é condizente com uma evolução de magmas básicos por cristalização fracionada de minerais máficos. Contudo, o aumento dos conteúdos da maioria dos HFSE do G1 ao G3 se dá em degraus (e.g., Zr e Nb; Figuras 7d e 7e), sugerindo uma possível evolução distinta. Além de apresentar os maiores conteúdos de HFSE, as amostras G3 (390, 531C, 480) apresentam conteúdos anômalos da maioria destes elementos (e.g., Y, Nb e Zr; Figuras 7c a 7e; Tabela 1).

O diagrama de Winchester e Floyd (1977) (Figura 8), que usa a razão $\mathrm{Zr} / \mathrm{TiO}_{2}$ como um índice de diferenciação e a razão $\mathrm{Nb} / \mathrm{Y}$ como um discriminante de alcalinidade ressalta a assinatura subalcalina dos metabasitos do Grupo Votuverava. Neste diagrama a ampla maioria das amostras se posiciona no campo dos basaltos subalcalinos. Os três grupos apresentam agrupamentos distintos neste gráfico, com aumento progressivo da alcalinidade do G1 ao G3.

Os elementos litófilos de grande raio iônico (LILE large ion lithophile elements), representado na Figura $7 f$ pelo $\mathrm{Sr}$, apresentam tendências com correlações positivas confirmando o caráter incompatível.

Os padrões de ETR normalizados pelo condrito e multielementos normalizados pelo MORB mostram assinaturas distintas para os metabasitos de cada grupo (Figura 9).

As amostras G1 apresentam padrões de ETR sub-horizontais em geral com fraco enriquecimento em ETR leves (ETRL) em relação aos ETR pesados (ETRP), com $(\mathrm{La} / \mathrm{Yb})_{\mathrm{N}}$ entre 1,3 e 1,8. Duas amostras apresentaram razão $(\mathrm{La} / \mathrm{Yb})_{\mathrm{N}}$ de 0,9. A concentração dos ETR é de 3 a 13 vezes os valores condríticos. Ocorrem fracas anomalias negativas de Ce e positivas de Tb e Tm. A amostra 492 apresenta anomalia positiva de Eu. No diagrama multielementos, normalizado pelo MORB, as amostras G1 mostram empobrecimento dominantemente moderado 
Frederico Meira Faleiros et al.
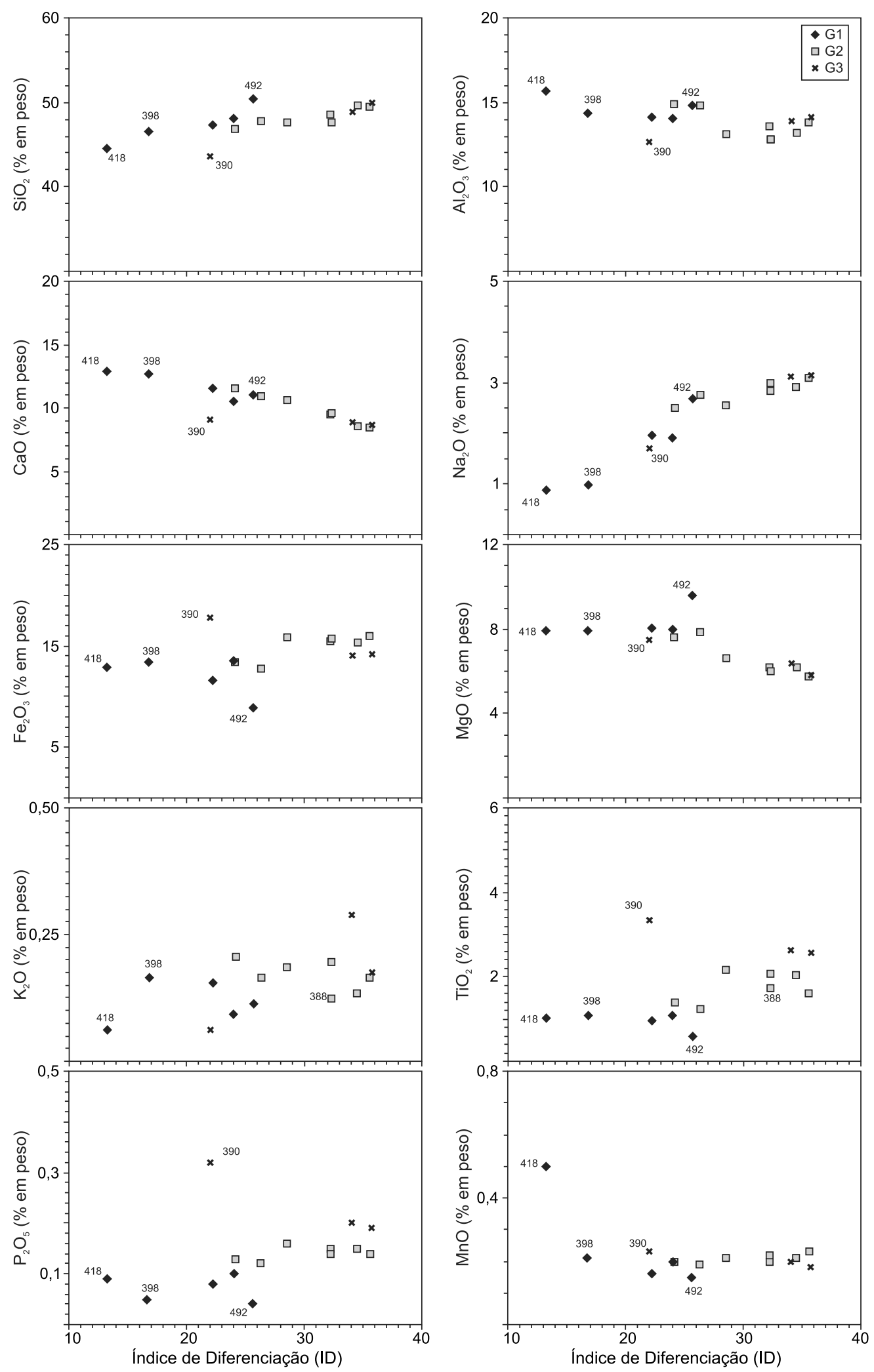

Figura 4. Diagramas binários relacionando o índice de diferenciação de Thornton e Tuttle (1960) (ID = Q $Z+A b+O r+$ $\mathrm{Ne}+\mathrm{Lct}+\mathrm{Kls}$ normativos) e elementos maiores. 
Tabela 2. Síntese dos testes para identificação de efeitos metassomáticos (Beswick e Soucie, 1978) e relação de teores anômalos de elementos maiores e traços.

\begin{tabular}{|c|c|c|c|c|c|}
\hline \multirow{2}{*}{ Amostra } & \multirow{2}{*}{ Grupo } & \multirow{2}{*}{ Ganho } & \multirow{2}{*}{ Perda } & \multicolumn{2}{|l|}{ Teores anômalos } \\
\hline & & & & Alto & Baixo \\
\hline $388 \mathrm{C}$ & 1 & $\mathrm{Na}_{2} \mathrm{O}$ & $\mathrm{CaO}$ & $\mathrm{Na}_{2} \mathrm{O}, \mathrm{MgO}, \mathrm{Cr}, \mathrm{Ni}, \mathrm{Ba}$ & $\mathrm{Ga}, \mathrm{P}_{2} \mathrm{O}_{5}, \mathrm{Fe}_{2} \mathrm{O}_{3}$ \\
\hline 390 & 3 & & & $\mathrm{TiO}_{2}, \mathrm{P}_{2} \mathrm{O}_{5}, \mathrm{Fe}_{2} \mathrm{O}_{3}, \mathrm{Co}, \mathrm{Ni}, \mathrm{Cu}, \mathrm{ETR}, \mathrm{HFSE}, \mathrm{Th}, \mathrm{U}, \mathrm{Au}$ & $\mathrm{Al}_{2} \mathrm{O}_{3}, \mathrm{SiO}_{2}, \mathrm{CaO}$ \\
\hline 398 & 1 & $\mathrm{CaO}$ & $\mathrm{Na}_{2} \mathrm{O}$ & & \\
\hline 418 & 1 & $\mathrm{CaO}$ & $\mathrm{Na}_{2} \mathrm{O}$ & $\mathrm{MnO}$ & \\
\hline 492 & 1 & & & $\mathrm{SiO}_{2}, \mathrm{MgO}, \mathrm{Cr}$ & $\mathrm{Fe}_{2} \mathrm{O}_{3}, \mathrm{TiO}_{2}, \mathrm{P}_{2} \mathrm{O}_{3}, \mathrm{Ga}$ \\
\hline 499B & 1 & $\mathrm{CaO}$ & $\mathrm{Na}_{2} \mathrm{O}$ & $\mathrm{Sr}$ & $\mathrm{MgO}, \mathrm{Fe}_{2} \mathrm{O}_{3}$ \\
\hline $501 \mathrm{~B}$ & 2 & $\mathrm{~K}_{2} \mathrm{O}$ & & $\mathrm{Al}_{2} \mathrm{O}_{3}, \mathrm{SiO}_{2}, \mathrm{CaO}, \mathrm{K}_{2} \mathrm{O}$ & $\mathrm{Fe}_{2} \mathrm{O}_{3}, \mathrm{TiO}_{2}, \mathrm{P}_{2} \mathrm{O} 5$ \\
\hline $514 \mathrm{~B}$ & 1 & $\mathrm{Na}_{2} \mathrm{O}$ & $\mathrm{CaO}$ & $\mathrm{Na}_{2} \mathrm{O}, \mathrm{Al}_{2} \mathrm{O}_{3}, \mathrm{MgO}, \mathrm{MnO}, \mathrm{Pb}$ & \\
\hline 531 & anômala & & & $\mathrm{TiO}_{2}, \mathrm{Fe}_{2} \mathrm{O}_{3}, \mathrm{~V}$ & $\mathrm{Na}_{2} \mathrm{O}, \mathrm{MgO}, \mathrm{HSFE}$ \\
\hline
\end{tabular}

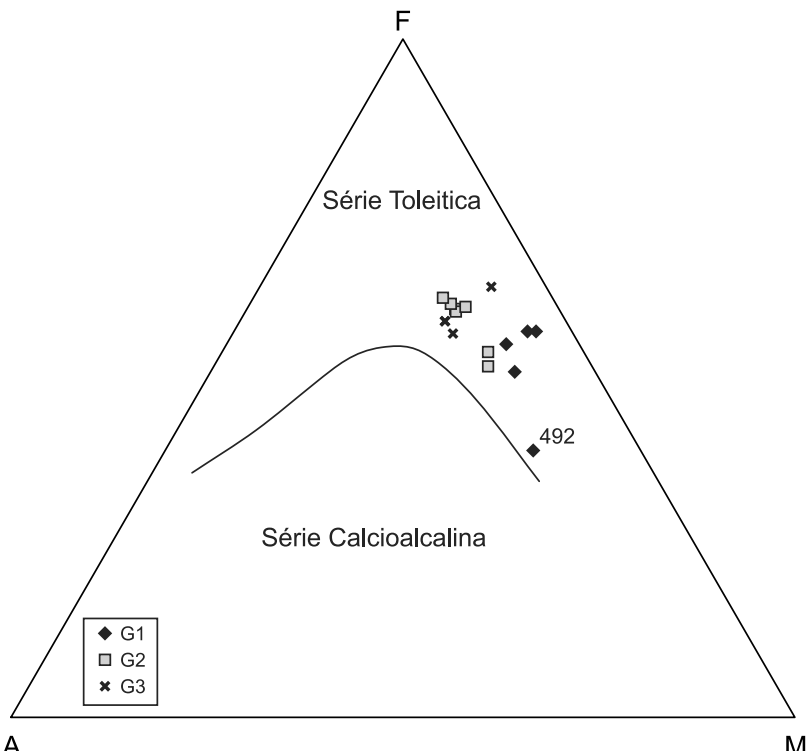

Figura 5. Diagrama classificatório AFM (Irvine e Baragar, 1971) com dados dos metabasitos do Grupo Votuverava.

em HFSE (de Nb a Yb). A amostra 492 apresenta empobrecimento forte de $\mathrm{Ta}$ a $\mathrm{Yb}$. Os valores de Ta e, em alguns casos, de Th e Nd estão aproximadamente nos níveis dos valores N-MORB de normalização para a maioria das amostras. Os LILE apresentam comportamento complexo para o G1. O Ba e o Th apresentam comportamentos mais coerentes, com enriquecimento de até 6 e 7 vezes os valores do N-MORB, respectivamente.

As amostras G2 apresentam padrões ETR sub-horizontais com leve enriquecimento em ETRL, com razão (La/ $\mathrm{Yb})_{\mathrm{N}}$ entre 1,1 e 1,9 . A concentração de ETR é de 10 a 25

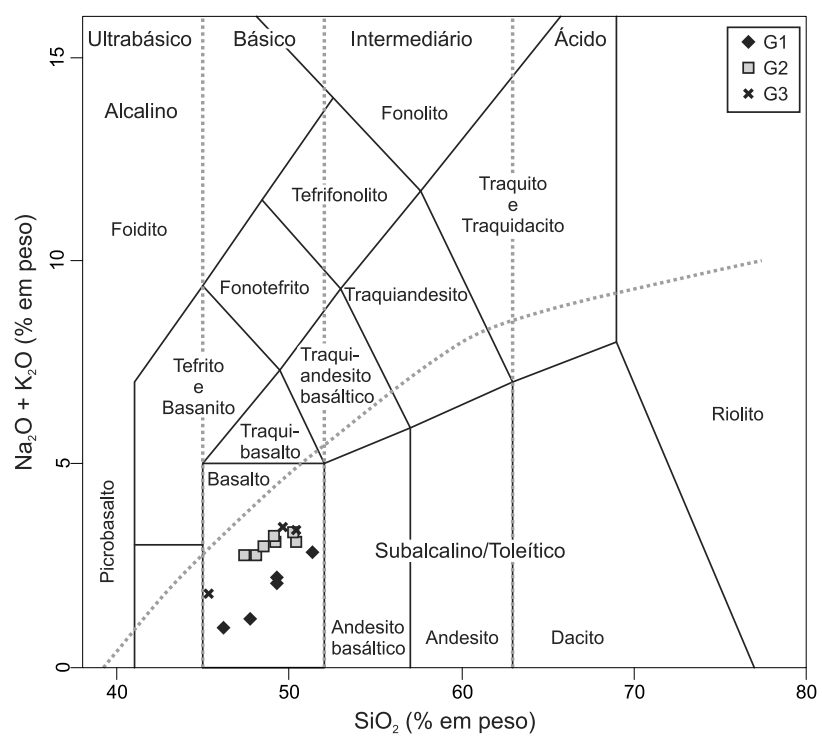

Figura 6. Diagrama classificatório TAS (Le Bas et al., 1986) com dados dos metabasitos do G rupo Votuverava.

vezes os valores do condrito. Ocorrem leves anomalias positivas de $\mathrm{Nd}$, Tb e Tm. Os padrões multielementos mostram conteúdos dos HFSE de $\mathrm{P}$ a Ti próximos aos valores do N-MORB, com geral empobrecimento em Zr, Y e Yb, e enriquecimento em $\mathrm{Ta}$ e $\mathrm{Nb}$. Ocorre geral enriquecimento em LILE, com algumas exceções e os teores de Th alcançam até 7 vezes os valores N-MORB.

As amostras G3 apresentam padrões ETR com forte enriquecimento de ETRL em relação aos ETRP, com valores $(\mathrm{La} / \mathrm{Yb})_{\mathrm{N}}$ entre 2,3 e 5,3. A concentração de ETR é bem superior ao das amostras G1 e G2, com teores de até 

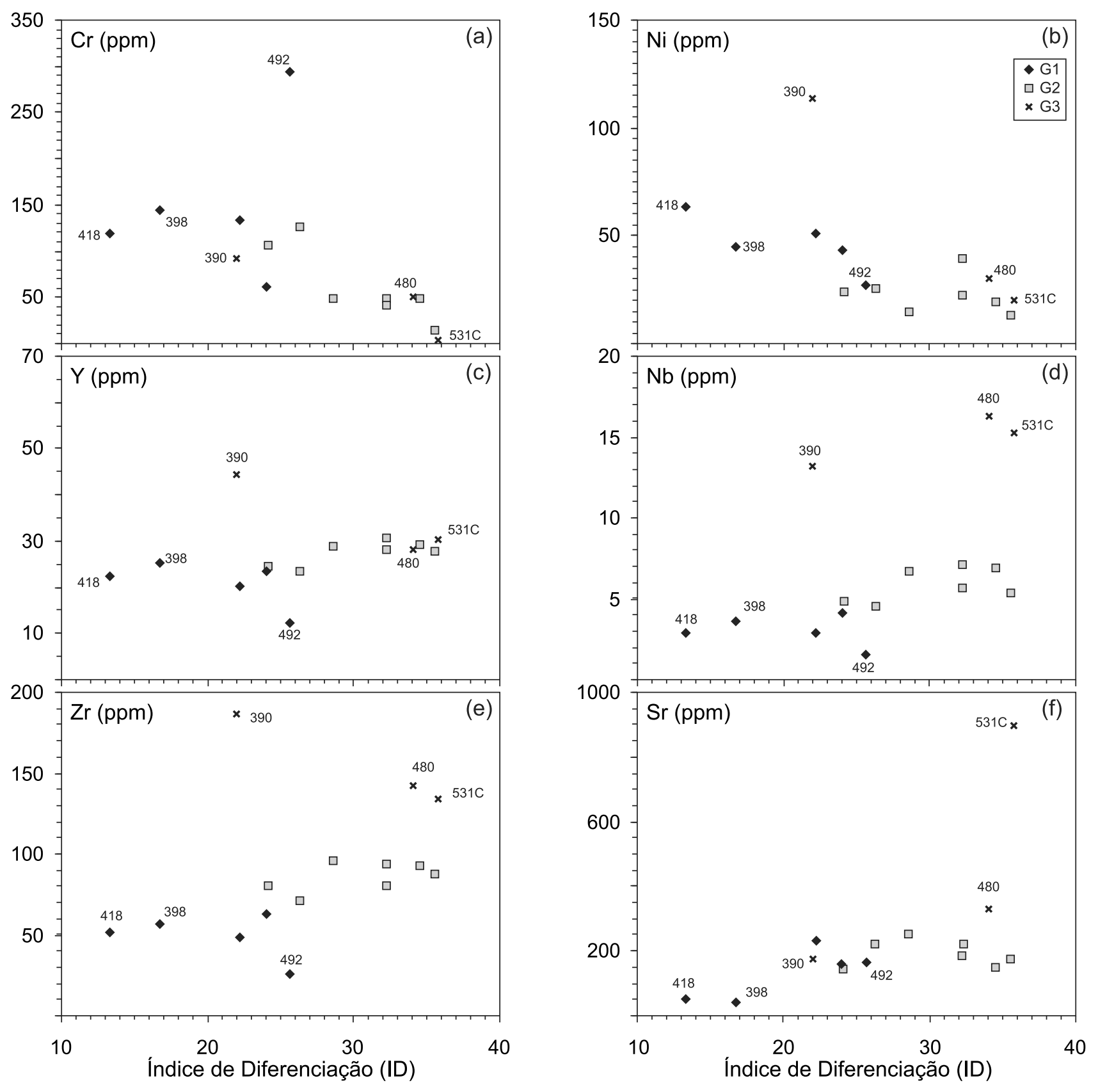

Figura 7. Diagramas binários relacionando o índice de diferenciação de Thornton e Tuttle (1960) (ID $=Q \square+A b+O r+$ $\mathrm{Ne}+$ Lct + Kls normativos) e elementos traços. 


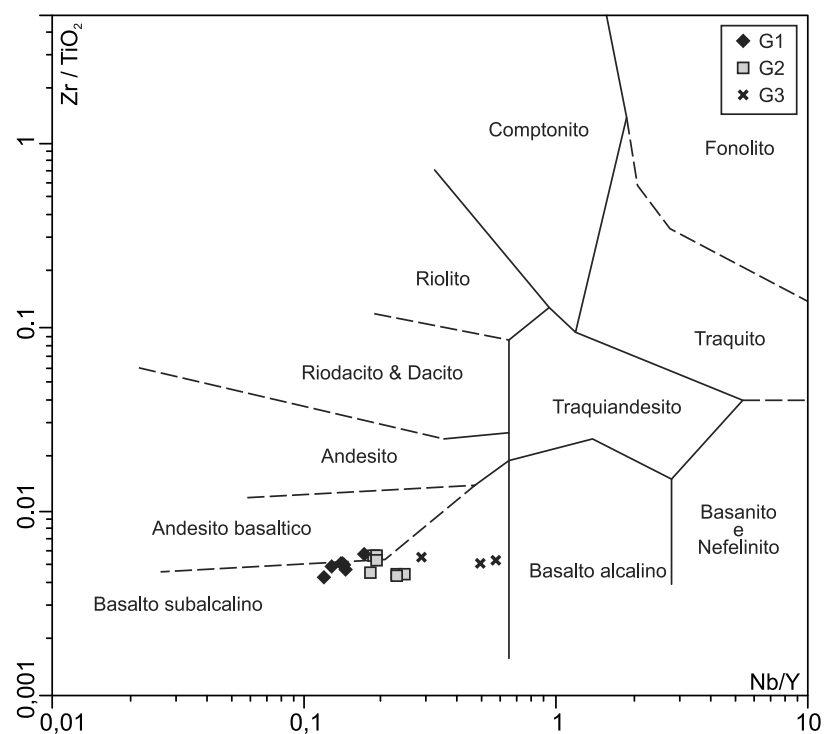

Figura 8. Diagrama de classificação $\mathrm{Nb} / \mathrm{Y}-\mathrm{Zr} / \mathrm{TiO}_{2}$ de Winchester e Floyd (1977) com dados de metabasitos do G rupo Votuverava.

60 vezes o condrito. A maioria das amostras apresenta leves anomalias positivas de $\mathrm{Nd}$, Tb e Tm. Os metabasitos G3 apresentam padrões multielementos com enriquecimento moderado dos HFSE de Ta a Ti, leve empobrecimento em $\mathrm{Yb}$ e teores de $\mathrm{Y}$ próximos aos valores de normalização. Em geral ocorre enriquecimento relativo dos LILE, embora as amostras apresentem empobrecimento em $\mathrm{K}$ e/ou Rb e/ou Ba. De maneira geral o comportamento dos LILE denuncia fenômenos de transformação sofridos por essas rochas.

\section{DISCUSSÃO}

\section{Evolução magmática}

Numa primeira análise as variações dos conteúdos dos elementos maiores frente aos valores do índice de diferenciação (ID) das amostras estudadas se ajustam aos padrões esperados para evolução por cristalização fraciona$\mathrm{da}$, onde as rochas do G1 representariam os líquidos mais primitivos e G3 os mais evoluídos. Contudo, a análise do comportamento dos elementos traços, principalmente os HFSE, sugere uma evolução distinta para os três grupos. A distinção entre os três grupos fica bastante evidente com relação aos valores da razão Ti/V (Figura 2). Shervais (1982) demonstra que os processos de cristalização fracionada de silicatos não afetam de maneira significativa a razão $\mathrm{Ti} / \mathrm{V}$, resultando em tendências de diferenciação para- lelas ou subparalelas às linhas de Ti/V constante. Líquidos mais evoluídos tendem a apresentar maiores razões $\mathrm{Ti} / \mathrm{V}$, porém, associadas a menores abundâncias de Ti e V (Shervais, 1982). Isso não ocorre para os grupos G1, G2 e G3. As amostras G1 e G2 formam alinhamentos seguindo razões Ti/V médias de aproximadamente 17 e 25 , respectivamente, e o G2 atinge abundâncias de Ti e V mais altas que o G1. O G3 forma um agrupamento com valor Ti/V de aproximadamente 40 .

A razão $\mathrm{Ti} / \mathrm{V}$ pode ser fortemente afetada no caso de cristalização fracionada de magnetita e/ou hornblenda (Shervais, 1982). Neste caso, o gráfico relacionando Si (ou Zr) e Ti (ou V) deve apresentar tendência com correlação negativa. Como mostrado na Figura 10, isso não ocorre no caso das amostras estudadas. No gráfico relacionando $\mathrm{Zr}$ e $\mathrm{TiO}_{2}$, todos os grupos apresentam tendências com fortes correlações positivas, porém, com diferentes inclinações para cada grupo (Figura 10).

Por outro lado, considerando cada grupo geoquímico separado as variações composicionais sugerem que a diferenciação interna de cada grupo se deu por cristalização fracionada de silicatos (plagioclásio e minerais máficos).

\section{Ambiência tectônica}

Conforme demonstrado por Shervais (1982) as razões Ti/V são diagnósticas de ambientes tectônicos distintos. A base do diagrama discriminante de ambiente tectônico relacionando Ti e V é a variação do coeficiente de partição cristal/líquido para o vanádio, que varia com aumento da fugacidade de oxigênio de $>1 \mathrm{a}<<1$. O empobrecimento de $\mathrm{V}$ em relação ao Ti é função da fugacidade de oxigênio do magma e de sua fonte, do grau de fusão parcial e subsequente cristalização fracionada (Shervais, 1982). Modelagens de fusão parcial e cristalização fracionada realizadas pelo autor indicam que a razão Ti/V de magmas primários derivados do manto aumenta com o decréscimo da fração de fundido produzida e com o aumento do coeficiente de partição do vanádio. Magmas primários produzidos por 20 - 30\% de fusão parcial sob condições relativamente redutoras (tais como nas dorsais meso-oceânicas) terão razões $\mathrm{Ti} / \mathrm{V}$ entre 20 e 50. Fundidos similares produzidos sob condições mais oxidantes (tais como no caso de arcos de ilhas) terão razões iniciais Ti/V entre 10 e 20. Rochas alcalinas apresentam razões Ti/V geralmente maiores que 50 . Basaltos de bacias retroarco apresentam variações da razão Ti/V entre 10 e 50, e Shervais (1982) ressalta que uma variação semelhante encontrada em uma suíte de amostras de uma área geograficamente restrita pode ser diagnóstica de um ambiente de bacia retroarco. Variação semelhante ocorre nas amostras do Grupo Votuverava, sugerindo um ambiente de bacia retroarco. 

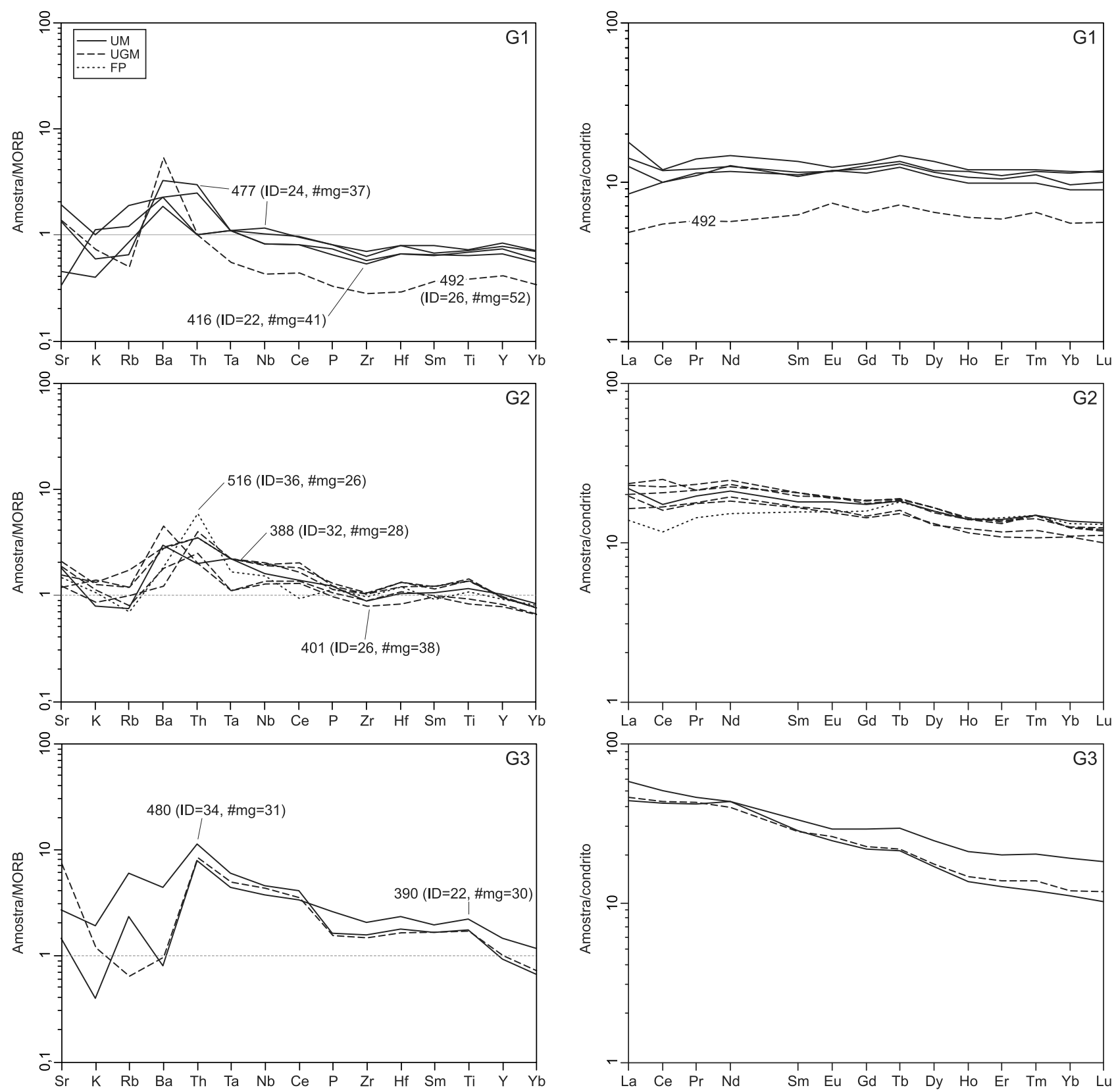

Figura 9. Padrões multielementos normalizados pelo MORB e de ETR normalizados pelo condrito para os metabasitos do Grupo Votuverava. Valores das normalizações segundo Pearce (1983) para multielementos e Boynton (1984) para ETR. 


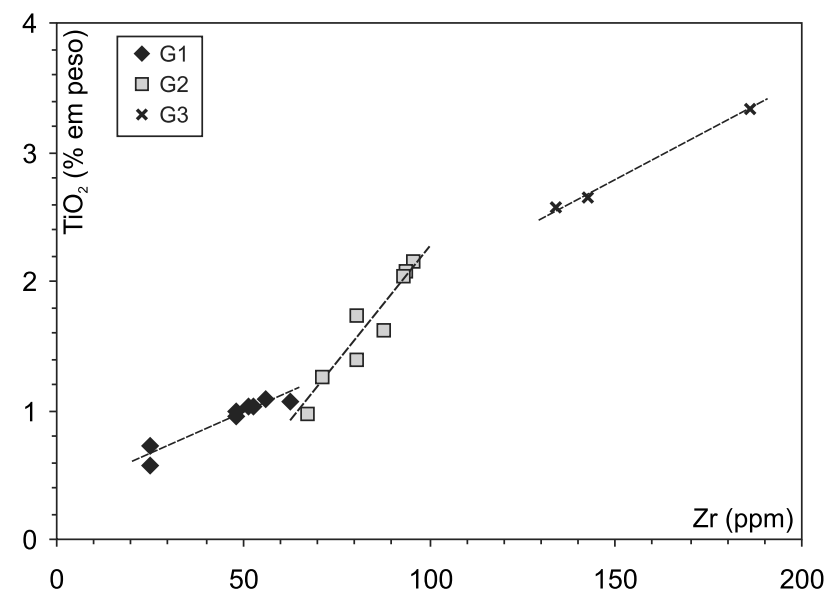

Figura 10. Diagrama binário relacionando $\mathrm{Zr}$ e TiO 2 para as amostras de metabasito do Grupo Votuverava.

Os padrões multielementos, normalizados pelo MORB, do G1 indicam contribuição importante do "componente de subducção", que é caracterizado pelo enriquecimento em LILE e empobrecimento em HFSE (e.g., Pearce e Peate, 1995). O padrão é semelhante àqueles encontrados em basaltos de arcos vulcânicos modernos. A presença de metabasitos de fácies xisto verde com hornblenda ígnea preservada no Grupo Votuverava (Maniesi, 1997; Maniesi e Oliveira, 2002; Oliveira et al., 2002; Faleiros e Campanha, 2004) pode ser considerada como uma outra evidência da presença de basaltos relacionados a arco vulcânico, uma vez que a grande maioria das ocorrências de hornblenda basalto está associada a esse ambiente tectônico (Barclay e Carmichael, 2004).

Em geral os padrões multielementos do G2 e do G3 são semelhantes aos padrões MORB e MORB enriquecido, respectivamente, embora os padrões do G2 possam estar associados a uma pequena contribuição do componente de subducção (forte enriquecimento nos LILE Ba e Th e empobrecimento em alguns HFSE).

A coexistência entre magmas com afinidades geoquímicas de arco vulcânico e de fundo oceânico e a ampla variação entre os valores Ti/V (15-40) converge para um ambiente de bacia retroarco para o magmatismo básico do Grupo Votuverava.

A coexistência entre magmas com afinidades de basaltos de arcos de ilhas e de dorsais meso-oceânicas já havia sido observada por Frasca et al. (1997) em estudo baseado principalmente na análise geoquímica de elementos maiores e poucos elementos traços. Entretanto, os autores observaram uma correlação espacial com metabasitos com assinaturas de basaltos de arcos de ilhas ao norte da Zona de Cisalhamento Ribeira e com assinaturas MORB ao sul.
No presente estudo, realizado em amostras coletadas exclusivamente ao sul da zona de cisalhamento, esse padrão não foi confirmado. Maniesi e Oliveira (2002) descrevem metabasitos com afinidades geoquímicas distintas associadas ao Grupo Votuverava na Região de Rio Branco do Sul (PR), ao sul da área do presente trabalho. Os metabasitos desta localidade apresentam teores de $\mathrm{MgO}$ de até 17,36\% e provavelmente representam rochas cumuláticas dominadas por clinopiroxênio (Maniesi e Oliveira, 2002).

Magmatismo básico associado à ambiente de bacia retroarco também foi interpretado para a Formação Água Clara e para o Grupo Lajeado (Maniesi e Oliveira, 2000), ambos integrantes do Terreno Apiaí. Contudo, os dados geocronológicos e de geoquímica isotópica disponíveis (Oliveira et al., 2002; Basei et al., 2003, 2008; Weber et al., 2004; Campanha et al., 2008a, 2008b, 2009; Siga Júnior et al., 2011) sugerem que estas duas unidades e o Grupo Votuverava não devem ter pertencido à mesma bacia (Faleiros, 2008).

\section{Fontes mantélicas e possíveis contaminações}

A variabilidade da razão $\mathrm{Ti} / \mathrm{Yb}$ é sensível à profundidade da fusão parcial que deu origem aos magmas básicos (Pearce, 2008). No diagrama binário $\mathrm{Nb} / \mathrm{Yb}-\mathrm{TiO}_{2} / \mathrm{Yb}$ as amostras G1 e G2 se posicionam principalmente no campo de composição de fonte mantélica do tipo MORB (normal e levemente enriquecido, respectivamente) (Figura 11a), revelando geração por fusão rasa. Além dos basaltos de dorsais meso-oceânicas esse padrão também é esperado para basaltos de arcos vulcânicos, uma vez que o titânio é um elemento conservativo para magmas de arco, ou seja, não existe contribuição detectável do componente de subducção para a fonte do magmatismo de arco com relação a este elemento (Pearce e Peate, 1995). Por outro lado, as amostras G3 se posicionam acima do campo de variação das fontes mantélicas do tipo MORB, sugerindo fusão mais profunda relacionada a interação com pluma (Pearce, 2008). O padrão de distribuição de todos os grupos neste diagrama define uma tendência diagonal de variação entre as composições médias do MORB normal e de basaltos de ilhas oceânicas, o que é típico de ambientes de dorsais meso-oceânicas próximas a plumas (e.g., Sistema Galápagos, Sistema Islândia-Dorsal Reykjanes, Dorsal Sulamericana-Antártica; Pearce, 2008). Padrão de variação semelhante ocorre na bacia retroarco oceânica East Scotia Ridge, com influência de magmatismo do tipo pluma associado à Ilha Bouvet (Fretzdorff et al., 2002; Pearce, 2008).

A variabilidade da razão $\mathrm{Th} / \mathrm{Yb}$ é sensível à composição da fonte do magmatismo básico e aos efeitos de contaminação crustal ou relacionados ao componente de sub- 
ducção (Pearce, 2008). O diagrama Nb/Yb-Th/Yb (Figura 11b) mostra uma tendência de enriquecimento progressivo da fonte mantélica do G1 ao G3 (de MORB normal a enriquecido). As amostras dos grupos G1 e G2 apresentam grande variação da razão $\mathrm{Th} / \mathrm{Yb}$ para valores aproximadamente constantes de $\mathrm{Nb} / \mathrm{Yb}$ (Figura 11b). Como o Th é um elemento não conservativo para magmas de arco, ou seja, existe uma contribuição detectável do componente de subducção para a fonte do magmatismo de arco com relação a este elemento (e.g., Pearce e Peate, 1995), os padrões do G1 e do G2 podem ser interpretados como relacionados ao

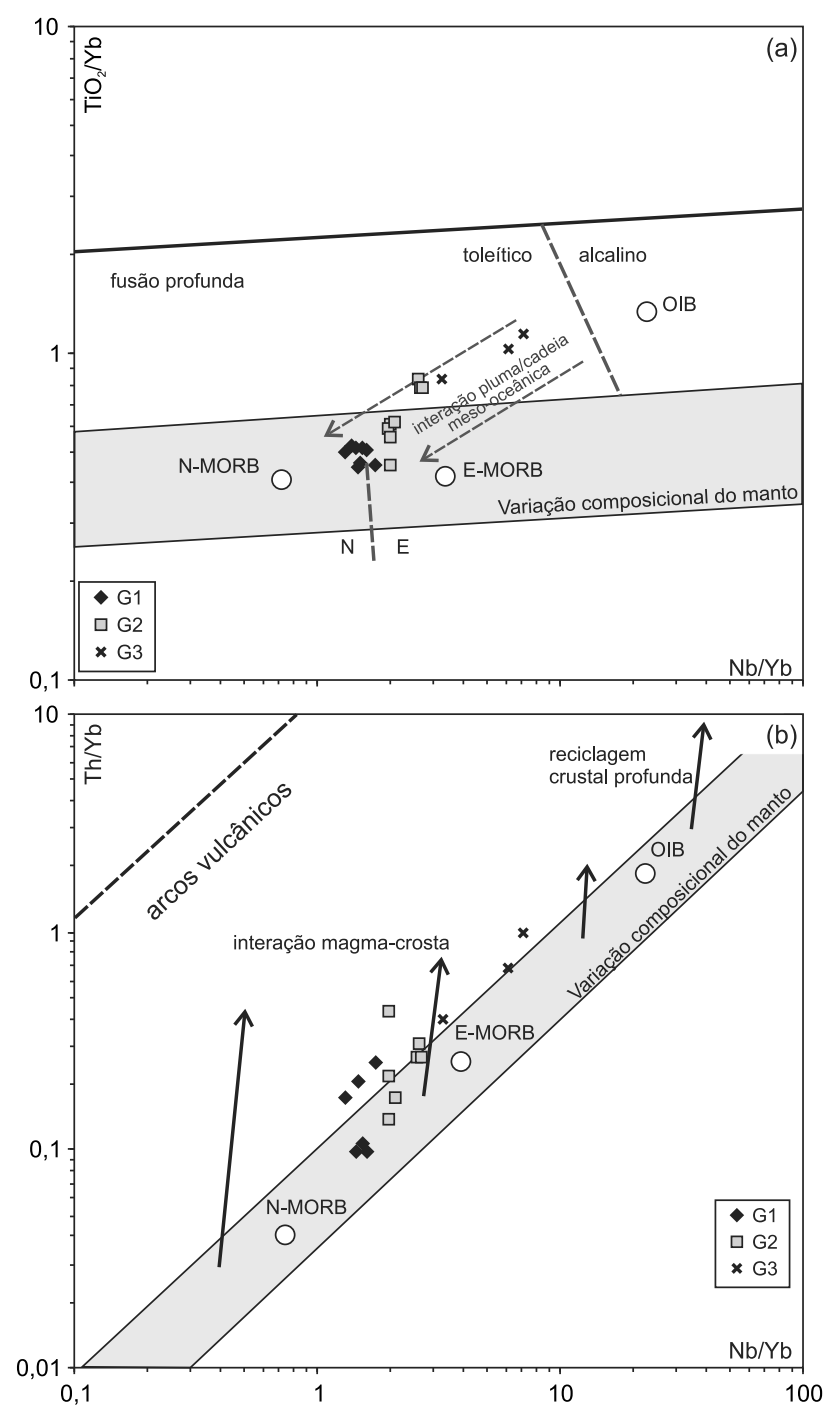

Figura 11. Diagramas Nb/Yb-TiO $2 / \mathrm{Yb}$ e Nb/Yb-Th/Yb petrogenéticos de Pearce (2008). Abreviações: N-MO RB, basaltos de cadeia meso-oceânica normais; E-MORB, basaltos de cadeia meso-oceânica enriquecidos; OIB, basaltos de ilhas oceânicas. componente de subducção. As amostras G3 se posicionam essencialmente no limite entre o campo dos basaltos de arcos vulcânicos e o campo de variação do manto.

A Figura 12 apresenta uma comparação entre o comportamento geoquímico dos metabasitos do Grupo Votuverava, de basaltos da bacia retroarco East Scotia Ridge e de basaltos do Arco de Ilhas Sandwich do Sul. Esse diagrama mostra uma grande semelhança entre o comportamento dos metabasitos do Grupo Votuverava e dos basaltos de East Scotia Ridge. A tendência (A) na Figura 12 foi interpretada como resultado de mistura de componentes de fonte MORB e pluma e/ou variado grau de fusão parcial do manto, enquanto a tendência (B) representada por mistura de fonte MORB e componente de subducção na geração dos basaltos da bacia retroarco East Scotia Ridge (Fretzdorff et al., 2002). Os metabasitos do Grupo Votuverava parecem ter passado por uma evolução semelhante, na qual os metabasitos G1 e G2 teriam sido gerados por interação de fonte MORB e componente de subducção e G3 por interação entre fontes do tipo MORB e pluma.

A variabilidade entre as razões $\mathrm{Th} / \mathrm{Nb}$ e $\mathrm{Ba} / \mathrm{Th}$ podem ser tentativamente utilizadas para se distinguir as possíveis características do componente de subducção. Grandes variações de $\mathrm{Th} / \mathrm{Nb}$ para valores pouco variáveis de $\mathrm{Ba} / \mathrm{Th}$ sugerem adição de material sedimentar subductado, enquanto

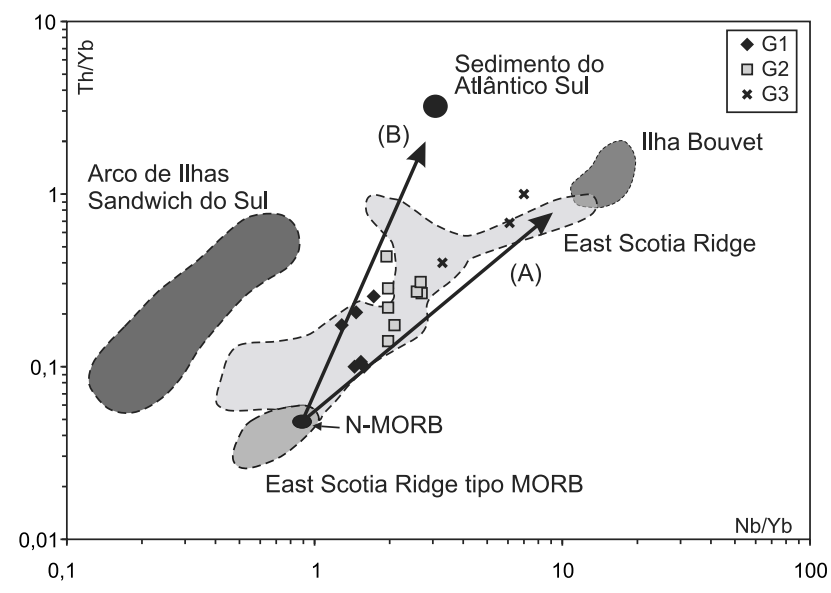

Figura 12. Diagrama de variação Nb/Y-Th/Yb (modificado de Fretzdorff et al., 2002) com comparação entre os dados dos metabasitos do Grupo Votuverava e basaltos da bacia retroarco East Scotia Ridge (ESR). A tendência $(A)$ foi interpretada como resultado de mistura de fontes associadas a MORB e pluma e/ou variado grau de fusão parcial do manto, enquanto a tendência (B) representada por mistura de fonte do tipo MO RB e componente de subducção na geração dos basaltos da bacia retroarco East Scotia Ridge (Fretzdorff et al., 2002). 
um padrão inverso sugere adição de fluido aquoso (Leat et al., 2000; Fretzdorff et al., 2002). O padrão de distribuição dos metabasitos G1 e G2 no diagrama Th/Nb-Ba/Th (Figura 13), com grande variabilidade da razão $\mathrm{Ba} / \mathrm{Th}$ para valores constantes de $\mathrm{Th} / \mathrm{Nb}$ pode ser interpretado como resultado de adição de fluido aquoso durante subducção. $\mathrm{O}$ padrão de distribuição dos metabasitos G1 e G2 se assemelha ao padrão dos basaltos da bacia retroarco East Scotia Ridge (Fretzdorff et al., 2002). As amostras G3 apresentam razões $\mathrm{Ba} / \mathrm{Th}$ abaixo dos valores $\mathrm{N}-\mathrm{MORB}$.

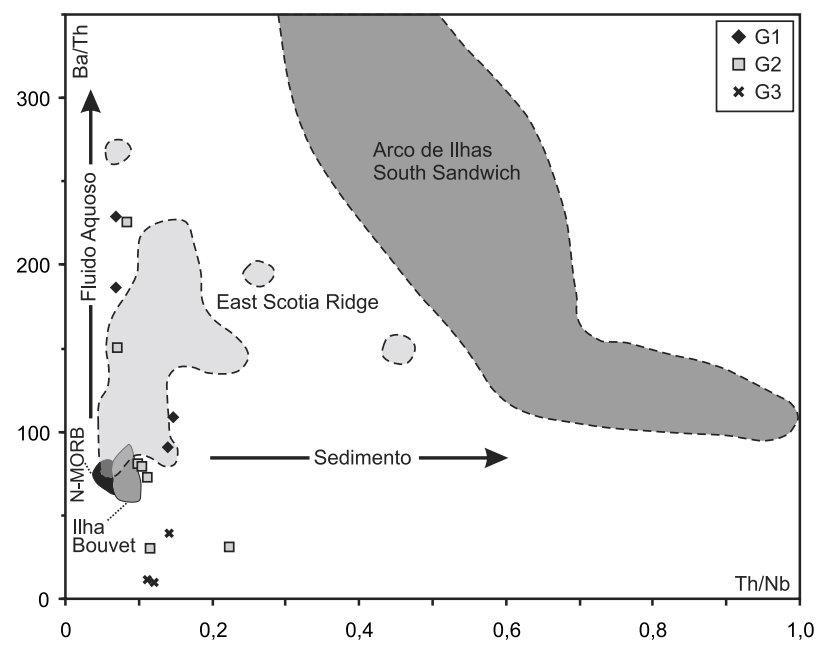

Figura 13. Diagrama Th/Nb-Ba/Th (modificado de Fretzdorff et al., 2002). Campos N-MO RB de Hofmann (1988), Sandwich do Sul de Pearce et al. (1995), Ilha Bouvet de Wea ver et al. (1987). As setas indicam as trajetórias interpretadas como relacionadas o enriquecimento devido à adição de fluido aquoso ou sedimento no componente de subducção (Leat et al., 2000).

\section{CONCLUSÕES}

Os metabasitos do Grupo Votuverava apresentam três assinaturas geoquímicas distintas: basaltos toleíticos de arcos de ilhas (G1), basaltos de dorsais meso-oceânicas normais a levemente enriquecidos (G2) e basaltos de dorsais meso-oceânicas enriquecidos (G3). A associação de rochas com estas três assinaturas geoquímicas em uma suíte de amostras de área geograficamente restrita sugere um ambiente de bacia retroarco para o Grupo Votuverava, o que é corroborado pelo ambiente sedimentar da unidade.

O comportamento dos elementos traços sugere que diferentes fontes estiveram envolvidas na geração dos metabasitos: interação entre fonte mantélica do tipo MORB normal e componente de subducção (G1); interação entre fonte mantélica do tipo MORB enriquecido e componente de subducção (G2); e interação entre fonte mantélica do tipo MORB e pluma (G3). A bacia retroarco oceânica East Scotia Ridge, com influência da pluma associada à Ilha Bouvet, pode ser considerada como um análogo moderno para o ambiente tectônico sugerido para o Grupo Votuverava.

\section{AGRADECIMENTOS}

Este trabalho foi financiado pelo Projeto Alto Ribeira (Geologia e Recursos Minerais da Folha Apiaí na escala 1:100.000), executado pelo Serviço Geológico do Brasil (CPRM), Superintendência Regional de São Paulo. Parte das amostras analisadas foi coletada pela Geóloga MSc Silvia Maria Morais (CPRM-SP). Os autores agradecem os comentários e sugestões de dois revisores da revista.

\section{REFERÊNCIAS}

BARCLAY, J.; CARMICHAEL, I. S. E. A Hornblende Basalt from Western Mexico: water-saturated phase relations constrain a pressure-temperature window of eruptibility. Journal of Petrology, v. 45, p. 485-506, 2004.

BASEI, M. A. S.; FRIMMEL, H. E.; NUTMAN, A. P.; PRECIOZZI, F. West Gondwana amalgamation based on detrital zircon ages from Neoproterozoic Ribeira and Dom Feliciano belts of South America and comparison with coeval sequences from SW Africa. Geological Society of London. Special Publications, v. 294, p. 239-256, 2008.

BASEI, M. A. S.; SIGA JÚNIOR, O.; MACHIAVELLI, A.; MANCINI, F. Evolução tectônica dos terrenos entre os cinturões Ribeira e Dom Feliciano (PR-SC). Revista Brasileira de Geociências, v. 22, p. 216-221, 1992.

BASEI, M. A. S.; SIGA JÚNIOR, O.; KAULFUSS, G. A.; CORDEIRO, H.; NUTMAN, A.; SATO, K.; CURY, L. F.; PRAZERES FILHO, H. J.; PASSARELLI, C. R.; HARARA, O. M.; REIS NETO, J. M.; WEBER, W. Geochronology and isotope geochemistry of Votuverava and Perau Mesoproterozoic basins, Southern Ribeira Belt, Brazil. In: SOUTH AMERICAN SYMPOSIUM ON ISOTOPE GEOLOGY, 4., 2003, Salvador. Short Papers... Salvador: CBPM, 2003, p. 501-504.

BESWICK, A. E.; SOUCIE, G. A correction procedure for metasomatism in an Archean greenstone belt. Precambrian Research, v. 6, p. 235-246, 1978. 
BIGARELLA, J. J.; SALAMUNI, R. Estudos preliminares na Série Açungui. VIII. A Formação Votuverava. Curitiba, Instituto de História Natural, 6 p. (Boletim. Geologia, 2), 1958.

BOYNTON, W. V. Cosmochemistry of the rare earth elements: meteorite studies. In: HENDERSON, P. (Ed.). Rare Earth Element Geochemistry. Amsterdam: Elsevier, 1984. p. 63-114.

BRITO NEVES, B. B.; CAMPOS NETO, M. C.; FUCK, R. A. From Rodinia to Western Gondwana: An approach to the Brasiliano-Pan African Cycle and orogenic collage. Episodes, v. 22, p. 155-166, 1999.

CAMPANHA, G. A. C. Tectônica proterozóica no Alto e Médio Vale do Ribeira, Estados de São Paulo e Paraná. 1991. 296 f. Tese (Doutorado) - Instituto de Geociências, Universidade de São Paulo, São Paulo, 1991.

CAMPANHA, G. A. C. O papel do sistema de zonas de cisalhamento transcorrentes na configuração da porção meridional da Faixa Ribeira. 2002. 105 f. Tese (Livre Docência) - Instituto de Geociências, Universidade de São Paulo, São Paulo, 2002.

CAMPANHA, G. A .C.; BRITO NEVES, B. B. Frontal and oblique tectonics in the Brazilian shield. Episodes, v. 27, 255-259, 2004.

CAMPANHA, G. A. C., FALEIROS, F. M. Neoproterozoic terrane collage in the southern and central Ribeira Belt, Brazil. In: INTERNATIONAL GONDWANA SYMPOSIUM, 12., 2005, Mendoza. Gondwana 12 conference: geological and biological heritage of Gondwana... Mendoza: Academia Nacional de Ciencias, 2005 , v. 1, p. 81.

CAMPANHA G. A. C.; SADOWSKI G. R. Tectonics of the Southern Portion of the Ribeira Belt (Apiaí Domain). Precambrian Research, v. 98, p. 31-51, 1999.

CAMPANHA, G. A. C.; BASEI, M. A. S.; FALEIROS, F. M.; TASSINARI, C. C. G.; NUTMAN, A. P.; VASCONCELOS, P. M.; DANTAS, E. L. Geocronologia do Terreno Apiaí no Sul do Estado de São Paulo. In: Simpósio 45 anos de Geocronologia no Brasil. 2009, São Paulo. Boletim de Resumos Expandidos... São Paulo: IGcUSP, 2009. p. 220-221.

CAMPANHA, G. A. C.; BASEI, M. S.; TASSINARI, C. C.; NUTMAN, A. P.; FALEIROS, F. M. Constraining the age of the Iporanga Formation with SHRIMP U-Pb zircon: implications for possible Ediacaran glaciation in the Ribeira Belt, SE Brazil. Gondwana Research, v. 13, p. 117-125, 2008a.

CAMPANHA, G. A. C.; BASEI, M. A. S.; TASSINARI, C. C. G.; NUTMAN, A. P.; FALEIROS, F. M. U-Pb SHRIMP and Sm-Nd analysis for Ribeira Belt Mesoproterozoic and Neoproterozoic terranes. In: SOUTH AMERICAN SYMPOSIUM ON ISOTOPE GEOLOGY, 6., 2008b, San Carlos de Bariloche. Short Paper... Buenos Aires: Ingeis, 2008b, 4 p. 1 CD-ROM.

CAMPANHA, G. A. C.; BISTRICHI, C. A.; ALMEIDA, M. A. Considerações sobre a organização litoestratigráfica e evolução tectônica da Faixa de Dobramentos Apiaí. In: SIMPÓSIO SUL-BRASILEIRO DE GEOLOGIA, Curitiba, 1987. Atas... Curitiba: SBG, 1987, v. 2, p. 725-742.

CAMPOS NETO, M. C.; FIGUEIREDO, M. C. H. The Rio Doce Orogeny, Southeastern Brazil. Journal of South American Earth Sciences, v. 8, p. 143-162, 1995.

CONEY, P. J.; JONES, D. L.; MONGER, J. W. H. Cordilleran suspect terranes. Nature, v. 288, p. 329-333, 1980.

CURY, L. F. Geologia do Terreno Paranaguá. 2009. 187 f. +3 mapas. Tese (Doutorado) - Instituto de Geociências, Universidade de São Paulo, São Paulo, 2009.

CURY, L. F.; KAULFUSS, G. A.; SIGA JÚNIOR, O.; BASEI, M. A. S.; HARARA, O. M. M.; SATO, K. Idades $\mathrm{U}-\mathrm{Pb}$ (zircões) de $1.75 \mathrm{Ga}$ em Granitóides Alcalinos Deformados dos Núcleos Betara e Tigre: Evidências de Regimes Extensionais do Estateriano na Faixa Apiai. Geologia USP. Série Científica, v. 2, p. 95-108, 2002.

DAITX, E. C. Origem e evolução dos depósitos sulfetados tipo Perau (Pb-Zn-Ag), com base nas jazidas Canoas e Perau (Vale do Ribeira - PR). 1996. 453 f. Tese (Doutorado) - Instituto de Geociências e Ciências Exatas, Rio Claro, 1996.

DÜRR, S. B.; DINGELDEY, D. P. The Kaoko belt (Namibia): part of a late Neoproterozoic continental-scale strike-slip system. Geology, v. 24, p. 503-506, 1996.

EGYDIO-SILVA, M.; VAUCHEZ, A.; BASCOU, J.; HIPPERTT, J. High-temperature deformation in the Neoproterozoic transpressional Ribeira belt, southeast Brazil. Tectonophysics, v. 352, p. 203-224, 2002. 
FALEIROS, F. M. Evolução de terrenos tectonometamórficos da Serrania do Ribeira e Planalto Alto Turvo (SP, PR). 2008, 306 f. Tese (Doutorado) - Instituto de Geociências, Universidade de São Paulo, São Paulo, 2008.

FALEIROS, F. M.; CAMPANHA, G. A. C. Petrografia e microestruturas de tectonitos da Zona de Cisalhamento Ribeira, Vale do Ribeira, SP e PR: implicações no zoneamento metamórfico e estrutural do Supergrupo Açungui e unidades correlatas. Revista Brasileira de Geociências, v. 34, p. 419-430, 2004.

FALEIROS, F. M.; CAMPANHA, G. A. C.; BELLO, R. M. S.; FUZIKAWA, K. Fault-valve action and vein development during strike-slip faulting: an example from the Ribeira Shear Zone, Southeastern Brazil. Tectonophysics, v. 438, p. 1-32, 2007.

FALEIROS, F. M.; CAMPANHA, G. A. C.; BELLO, R. M. S.; FUZIKAWA, K. Quartz recrystallization regimes, c-axis texture transitions and fluid inclusion reequilibration in a prograde greenschist to amphibolite facies mylonite zone (Ribeira Shear Zone, SE Brazil). Tectonophysics, v. 485, p. 193-214, 2010.

FALEIROS, F. M.; CAMPANHA, G. A. C.; MARTINS, L.; VLACH, S. R. F.; VASCONCELOS, P. M. Ediacaran high-pressure collision metamorphism and tectonics of the southern Ribeira Belt (SE Brazil): evidence for terrane accretion and dispersion during Gondwana assembly. Precambrian Research, 2011, doi:10.1016/j. precamres.2011.07.013.

FALEIROS, F. M.; MORAIS, S. M.; COSTA, V. C. Litoestratigrafia. In: FALEIROS, F. M.; COSTA, V. C. (Org.). Geologia e Recursos Minerais da Folha Apiaí escala 1:100.000, Estados de São Paulo e Paraná. São Paulo: Programa Geologia do Brasil, Levantamentos Geológicos Básicos, CPRM - Serviço Geológico do Brasil, 2010, cap. 4, 126 p.

FASSBINDER, E. A Unidade Água Clara no Contexto do Grupo Acungui: um modelo transpressivo de colisão obliqua no neoproterozoico Paranaense. 1996. 207 f. Tese (Doutorado) - Instituto de Geociências, Universidade de São Paulo, São Paulo, 1996.

FRASCÁ, M. B. H. O.; CAMPANHA, G. A. C.; FIGUEIREDO, M. C. H.; SADOWSKI, G. R. Geoquímica e ambiência tectônica de metabasitos do alto e médio Vale do Ribeira, São Paulo e Paraná. Revista Brasileira de Geociências, v. 27, p. 41-48, 1997.
FRETZDORFF, S.; LIVERMORE, R. A.; DEVEY, C. W.; LEAT, P. T.; STOFFERS, P. Petrogenesis of the Backarc East Scotia Ridge, South Atlantic Ocean. Journal of Petrology, v. 43, p. 1435-1467, 2002.

FUCK, R. A., BRITO NEVES, B. B., SCHOBBENHAUS, C. Rodinia descendants in South America. Precambrian Research, v. 160, p. 108-126, 2008.

HACKSPACHER, P. C.; DANTAS, E. L.; SPOLADORE, A.; FETTER, A. H.; OLIVEIRA, M. A. F. Evidence for Neoproterozoic backarc basin development in the central Ribeira Belt, southeastern Brazil: new geochronological and geochemical constraints from the São RoqueAçungui groups. Revista Brasileira de Geociências, v. 30, p. 110-114, 2000.

HARARA, O. M. M. Mapeamento e Investigação Petrológica e Geocronológica dos Litotipos da Região do Alto Rio Negro (PR-SC): um exemplo de sucessivas e distintas atividades magmáticas durante o Neoproterozóico III. 2001. 206 f. + anexos, + mapas. Tese (Doutorado) - Instituto de Geociências, Universidade de São Paulo, São Paulo, 2001.

HEILBRON, M; MACHADO, N. Timing of terrane accretion in the Neoproterozoic-Eopaleozoic Ribeira orogen (se Brazil). Precambrian Research, v. 125, p. 87-112, 2003.

HEILBRON, M.; DUARTE, B. P.; VALERIANO, C. M.; SIMONETTI, A.; MACHADO, N.; NOGUEIRA, J. R. Evolution of reworked Paleoproterozoic basement rocks within the Ribeira belt (Neoproterozoic), SE-Brazil, based on U-Pb geochronology: Implications for paleogeographic reconstructions of the São Francisco-Congo paleocontinent. Precambrian Research, v. 178, p. 136-148, 2010.

HEILBRON, M.; PEDROSA-SOARES, A. C.; CAMPOS NETO, M. C.; SILVA, L. C.; TROUW, R. A. J.; JANASI, V. A. Província Mantiqueira. In: MANTESSO-NETO, V.; BARTORELli, A.; CARNEIRO, C. D. R.; BRITONEVES, B. B. Geologia do Continente Sul-Americano: evolução da Obra de Fernando Flávio Marques de Almeida, p. 203-234, 2004.

HOFMANN, A. W. Chemical differentiation of the Earth: the relationship between mantle, continental crust, and oceanic crust. Earth and Planetary Science Letters, v. 90, p. 297-314, 1988.

HOWELL, G. H. Principles of terrenes analysis: new applications for global tectonics. London: Chapman e Hall, 1995. 245 p. (Topics in the earth sciences, 8). 
IRVINE, T. N.; BARAGAR, W. R. A. A guide to the chemical classification of the common volcanic rocks. Canadian Journal of Earth Sciences, v. 8, p. 523-548, 1971.

JANASI, V. A.; LEITE, R. J.; VAN SCHMUS, W. R. $\mathrm{U}-\mathrm{Pb}$ chronostratigraphy of the granitic magmatism in the Agudos Grandes Batholith (west of São Paulo, Brazil) implications for the evolution of the Ribeira Belt. Journal of South American Earth Sciences, v. 14, p. 363-376, 2001.

LE BAS, M. J.; LE MAITRE, R. W.; STRECKEISEN, A.; ZANETTIN, B. A Chemical Classification of Volcanic Rocks Based on the Total Alkali-Silica Diagram. Journal of Petrology, v. 27, p. 745-750, 1986.

LEAT, P. T.; LIVERMORE, R. A.; MILlAR, I. L.; PEARCE, J. A. Magma supply in back-arc spreading centre segment E2, East Scotia Ridge. Journal of Petrology, v. 41, 845-866, 2000.

MANIESI, V. Petrologia das rochas anfibolíticas das regiões de Adrianópolis, Campo Largo e Rio Branco do Sul/PR. 1997. 215 f. Tese (Doutorado) - Instituto de Geociências e Ciências Exatas, Universidade Estadual Paulista, Rio Claro, 1997.

MANIESI, V.; OLIVEIRA, M. A. F. Petrogênese dos metabasitos com afinidades dos toleítos de fundo oceânico das regiões de Adrianópolis e Campo Largo/PR. Revista Brasileira de Geociências, v. 30, p. 607-614, 2000.

MANIESI, V.; OLIVEIRA, M. A. F. Metabasitos com afinidades dos basaltos komatííticos da região de Rio Branco do Sul/PR. Revista Brasileira de Geociências, v. 32, p. 163-168, 2002.

MCWILLIAMS, M. O.; HOWELL, D. G. Exotic terranes of western California. Nature, v. 297, p. 215-217, 1982.

OLIVEIRA, M. A. F.; MANIESI, V.; TEIXEIRA, W.; DAITX, E. C. Caracterização isotópica de metabasitos e anfibolitos dos grupos Açungui e Setuva na Porção Sul da Faixa Ribeira. Geologia USP. Série Científica, v. 2, p. 161-170, 2002.

PEARCE, J. A. Role of the sub-continental lithosphere in magma genesis at active continental margins. In: HAWKESWORTH, C. J.; NORRY, M. J. (Ed.). Continental basalts and mantle xenoliths. Shiva, Nantwich, 230-249, 1983.

PEARCE, J. A. Geochemical fingerprinting of oceanic basalts with applications to ophiolite classification and the search for Archean oceanic crust. Lithos, v. 100, p. 14-48, 2008.

PEARCE, J. A.; PEATE, D. W. Tectonic implications of the composition of volcanic arc magmas. Annual Reviews in Earth and Planetary Sciences, v. 23, p. 251-285, 1995. PEARCE, J. A.; BAKER, P. E.; HARVEY, P. K.; LUFF, I. W. Geochemical evidence for subduction fluxes, mantle melting and fractional crystallization beneath the South Sandwich island arc. Journal of Petrology, v. 36, p. 1073-1109, 1995.

PIRES, F. A. Uma nova concepção para os ambientes do Grupo Açungui, na região de Iporanga e Apiaí, Sul de São Paulo. In: CONGRESSO BRASILEIRO DE GEOLOGIA, 35., 1988, Belém. Anais... Belém: SBG, 1988, v.2, p. 606-616.

PERROTTA, M. M. Potencial aurífero de uma região no Vale do Ribeira, São Paulo, estimado por modelagem de dados geológicos, geofísicos, geoquímicos e de sensores remotos num sistema de informações geográficas. 1996. 149 f. Tese (Doutorado) - Instituto de Geociências, Universidade de São Paulo, São Paulo, 1996.

PRAZERES FILHO, H. J. Caracterização geológica e petrogenética do Batólito Granítico Três Córregos (PR$\mathrm{SP})$ : geoquímica isotópica (Nd-Sr-Pb), idades (ID-TIMS/ SHRIMP) e $\delta 180$ em zircão. 2005. 207 f. Tese (Doutorado) - Instituto de Geociências, Universidade de São Paulo, São Paulo, 2005.

REIS NETO, J. M. Faixa Itaiacoca: registro de uma colisão entre dois blocos continentais no Neoproterozóico. 1994. 296 f. Tese (Doutorado) - Instituto de Geociências, Universidade de São Paulo, São Paulo, 1994.

SADOWSKI, G. R. A megafalha de Cubatão no Sudeste Brasileiro. Boletim IG-USP. Série Científica, v. 22, p. 15-28, 1991.

SATO, K.; SIGA JÚNIOR, O.; NUTMAN, A. P.; BASEI, M. A. S.; MCREATH, I.; KAULFUSS, G. A. The Atuba Complex, Southern South American Platform: Archean Components and Paleoproterozoic to Neoproterozoic Tectonothermal Events. Gondwana Research, v. 6, n. 2, p. 251-263, 2003.

SATO, K.; SIGA JUNIOR, O.; SILVA, J. A.; MCREATH, I.; DUNYI, L.; IIZUKA, T.; RINO, S.; HIRATA, T.; SPROESSER, W.; BASEI, M. A. S. In situ isotopic analyses of $\mathrm{U}$ and $\mathrm{Pb}$ in zircon by remotely operated 
SHRIMP II, and Hf by LA-ICP-MS: an example of dating and genetic evolution of zircon by $176 \mathrm{Hf} / 177 \mathrm{Hf}$ from the Ita Quarry in the Atuba Complex, SE Brazil. Geologia USP. Série Científica, v. 9, p. 61-69, 2009.

SCHERMER, E. R.; HOWELL, D. G.; JONES, D. L. The origin of allochthonous terranes: perspectives on the growth and shaping of continents. Annual Review of Earth and Planetary Sciences, v. 12, p. 107-131, 1984.

SHERVAIS, J. W. Ti-V plots and the petrogenesis of modern and ophiolitic lavas. Earth and Planetary Science Letters, v. 59, n. 1, p. 101-118, 1982.

SIGA JÚNIOR, O. Domínios tectônicos do sudeste do Paraná e nordeste de Santa Catarina: geocronologia e evolução crustal. 1995. 212 f. Tese (Doutorado) - Instituto de Geociências, Universidade de São Paulo, São Paulo, 1995.

SIGA JÚNIOR, O.; BASEI, M. A. S.; PASSARELLI, C. R.; HARARA, O. M.; SATO, K.; CURY, L. F.; PRAZERES FILHO, H. J. Geocronologia de rochas gnáissico-migmatíticas e sienograníticas do Núcleo Setuva (PR): implicações tectônicas. Revista Brasileira de Geociências, v. 37, p. 114-128, 2007.

SIGA JUNIOR, O.; BASEI, M. A. S.; PASSARELLI, C. R.; SATO, K.; CURY, L. F.; MCREATH, I. Lower and Upper Neoproterozoic magmatic records in Itaiacoca Belt (Paraná-Brazil): Zircon ages and lithostratigraphy studies. Gondwana Research, v. 15, n. 2, p. 197-208, 2009.

SIGA JÚNIOR, O.; CURY, L. F.; MCREATH, I.; RIBEIRO, L. M. A. L.; SATO, K.; BASEI, M. A. S.; PASSARELLI, C. R. Geology and geochronology of the Betara region in south-southeastern Brazil: evidence for possible Statherian (1.80-1.75 Ga) and Calymmian (1.50$1.45 \mathrm{Ga})$ extension events. Gondwana Research, v. 19, n. 1, p. 260-274, 2011.

SILVA, L. C.; MCNAUGHTON, N. J.; ARMSTRONG, R.; HARTMANN, L. A.; FLETCHER, I. R. The Neoproterozoic Mantiqueira Province and its African connections: a zirconbased U-Pb geochronologic subdivision for the Brasiliano/ Pan-African systems of orogens. Precambrian Research, v. 136, n. 3-4, p. 203-240, 2005.

SOARES, P. C. Seqüências tectono-sedimentares e tectônica deformadora no centro-oeste do escudo paranaense. In: SIMPÓSIO SUL-BRASILEIRO DE GEOLOGIA, 3., 1987, Curitiba. Atas... Curitiba: SBG, 1987, v. 2, p. 743-771.
SOARES, P. C. Tectônica colisional em torno do Bloco Paraná, Brasil. In: CONGRESSO LATINOAMERICANO DE GEOLOGIA, 7., 1988, Belém. Anais... Belém: SBG, 1988, v. 1, p. 63-79.

THORNTON, C. P.; TUTTLE, O. F. Chemistry of igneous rocks I. Differentiation index. American Journal of Science, v. 258, p. 664-684, 1960.

WEAVER, B. L.; WOOD, D. A.; TARNEY, J.; JORON, J. L. Geochemistry of ocean island basalts from the South Atlantic: Ascension, Bouvet, St. Helena, Gough and Tristan da Cunha. Geological Society London. Special Publication, v. 30, 253-267, 1987.

WEBER, W.; SIGA JÚNIOR, O.; SATO, K.; REIS NETO, J. M.; BASEI, M. A. S.; NUTMAN, A. P. A Formação Água Clara na Região de Araçaiba-SP: Registro U-Pb de uma Bacia Mesoproterozóica. Geologia USP. Série Científica, v. 4, p. 101-110, 2004.

WINCHESTER, J. A.; FLOYD, P. A. Geochemical discrimination of different magma series and their differentiation products using immobile elements. Chemical Geology, v. 20, p. 325-343, 1977. 